Research Article

\title{
IBEM Simulation of Seismic Wave Scattering by a 3D Tunnel Mountain
}

\author{
Ping-Lin Jiang $\mathbb{D}^{1}{ }^{1}$ Hua Jiang $\mathbb{D},{ }^{1}$ Yu-Sheng Jiang, ${ }^{1}$ Dai Wang, ${ }^{2}$ Nan Li, ${ }^{2}$ and Zhong-He Shi ${ }^{1}$ \\ ${ }^{1}$ School of Mechanics and Civil Engineering, China University of Mining \& Technology, Beijing 100083, China \\ ${ }^{2}$ Tianjin Key Laboratory of Civil Buildings Protection and Reinforcement, Tianjin Chengjian University, Tianjin 300384, China
}

Correspondence should be addressed to Hua Jiang; jianghua@cumtb.edu.cn

Received 30 October 2020; Revised 15 December 2020; Accepted 17 January 2021; Published 3 February 2021

Academic Editor: Giuseppe Brandonisio

Copyright (C) 2021 Ping-Lin Jiang et al. This is an open access article distributed under the Creative Commons Attribution License, which permits unrestricted use, distribution, and reproduction in any medium, provided the original work is properly cited.

The seismic wave scattering by a 3D tunnel mountain is investigated by the indirect boundary element method (IBEM). Without loss of generality, the 3D physical model of hemispherical tunnel mountain in an elastic half-space is established, and the influence of the incidence frequency and angle of P or SV wave on the mountain surface displacements is mainly examined. It is shown that there exists quite a difference between the spatial distribution of displacement amplitude under the incident $\mathrm{P}$ wave and the one under SV wave and that the incidence frequency and angle of wave, especially the existence of tunnel excavated in the mountain, have a great effect on the surface displacements of mountain; the presence of the tunnel in the mountain may cause the greater amplification of surface displacement, which is unfavorable to the mountain projects. In addition, it should be noted that the tunnel may suffer the more severe damage under the incident SV wave.

\section{Introduction}

With the rapid development of economy, the highway, railway, and other infrastructures gradually extend to the mountainous area, and the mountain tunnel accounts for an increasing proportion in the line, for example, $70.2 \%$ in China Sichuan-Tibet railway and $86 \%$ in Japan central Shinkansen. A large number of theoretical research and earthquake damage investigations [1-5] have illustrated that the mountain/hill topography has a significant effect on the seismic surface motions, and, due to the scattering and interference of seismic waves inside the mountain, there exists a strong interaction between the tunnel and the mountain, which is of great importance for the seismic design of mountain tunnels.

The existence of mountain or tunnel will significantly change the spatial distribution characteristics of ground motion and affect the damage degree and the distribution of local ground motions [6-15]. At present, the seismic response analysis methods commonly used can be divided into the analytical methods and the numerical methods. In terms of the analytical methods, Mow and Pao [16] adopted the wave function expansion method to study the dynamic stress concentration of a single cavity in infinite space under the incidence of elastic wave. Lee and Trifunac $[17,18]$ further derived the analytical solution of the underground circular cavity to the incident SH wave. Yuan and Liao [19] gave a closed-form solution of two-dimensional scattering of plane $\mathrm{SH}$ waves by a cylindrical hill of circular-arc cross section in a half-space by the wave function expansion method and studied the effect of the height-to-width ratio of hill on surface ground motion. Smerzini et al. [11] conducted the effect of underground cavities on surface earthquake ground motions by considering the factors such as the cavity size, its embedment depth, the excitation frequency, and the incidence angle. Liang et al. [20-23] derived the analytical solution of the incident plane P and SV and SH waves by a semicylindrical hill, discussed the effect of incidence frequency and incidence angle on the surface motion of hill, and concluded that a hill greatly amplifies the incident plane wave. It is worth noting that the analytical methods mainly focus on the two-dimensional scattering of hill/tunnel, and there are relatively few studies on the seismic response of tunnel mountain. 
Compared with the analytical methods, the numerical methods are more suitable for complex models, including the finite difference method (FDM) [24-26], the finite element method (FEM) [27, 28], and the boundary element method (BEM) [29-32]. By the explicit finite element method, Li and Lu [33] established the model of underground caverns and studied the dynamic response of caverns, which is mainly determined by factors such as the characteristics of incident seismic wave, mountain topography, joint surface, and the caverns location. Zhu et al. [34] used the explicit finite difference method to analyze the influence of mountain topography and large geological structure on the seismic response of underground cavern and surrounding rock. Hao and Zhang [35] adopted the explicit finite element analysis method combined with the artificial transmitting boundary theory to evaluate the adjacent terrain effects on ground motion and found that the amplification of seismic waves by multimountain shape in a specific frequency band was more obvious than that by a single mountain. In terms of boundary element methods, Zhou and Chen $[36,37]$ studied the scattering effect of $P$ and $\mathrm{SV}$ and $\mathrm{SH}$ waves on irregular terrain and analyzed the amplification effect of terrain on ground motion qualitatively and quantitatively. Taking the large underground cavern as an example, Liu et al. [38] studied the dynamic interaction among multiple adjacent mountains by the dynamic indirect boundary element method and evaluated the amplification effect of ground motion for the incident $\mathrm{P}$ and SV waves.

It can be seen that the above-mentioned studies mainly focus on the $2 \mathrm{D}$ analysis or simple $3 \mathrm{D}$ topography, and the research on the amplification effect of $3 \mathrm{D}$ tunnel mountain is still poor. It is known that, compared with the finite element method and the finite difference method, the IBEM can accurately satisfy the radiation conditions at infinity without introducing the artificial boundary, and the boundary discretization is only needed. In addition, the identical precision can be reached for both stress and displacement, and no numerical dispersion at high frequency occurs. Therefore, in this paper, the indirect boundary element method (IBEM) is used to solve the 3D scattering of $\mathrm{P}$ and $\mathrm{SV}$ waves by tunnel mountain; on the basis of the precision validation, the influence of the incidence frequency and incidence angle of wave on 3D tunnel mountain surface displacement amplitude is discussed in detail for a typical calculation example, and the conclusions have important theoretical and practical significance for revealing the physical mechanism of wave propagation in the tunnel mountain and determining the seismic precautionary requirements of engineering structures on the tunnel mountain more reasonably.

\section{Physical Model}

The model of a 3D tunnel mountain in an elastic half-space is shown in Figure 1, in which L1, L2, and L3 refer to the horizontal surface boundary, the mountain boundary, and the tunnel boundary, respectively; $a$ and $a_{1}$ are the radii of hemispherical mountain and semicircular tunnel, respectively. The seismic wave is incident in $x$ - $z$ plane. Due to the spatial attenuation effect of the scattered wave, 5 times of the wavelength is taken to meet the calculation accuracy at the discrete range of surface.

\section{Numerical Formulation}

3.1. Representation of Integral Equation. In the absence of physical force, the equation of steady-state motion in the isotropic elastic solid medium is

$$
(\lambda+\mu) \nabla \nabla \cdot u+\mu \nabla^{2} u=-\rho \omega^{2} u
$$

where $\lambda$ and $\mu$ are the Lame constants, $u$ is the displacement vector, $\nabla$ is the Hamilton operator, $\nabla^{2}$ is the Laplace operator, $\rho$ is mass density, and $\omega$ is the circular frequency. The time factor $\exp (i \omega t)$ will be omitted hereafter.

By the single layer potential theory, in three dimensions, the displacement $u_{i}(x)$ and stress $t_{i}(x)$ of the scattered wave field at position $x$ in the $i$ direction can be expressed as the integration on a continuous surface $S$ [39], respectively, and are shown as follows:

$$
\begin{aligned}
& u_{i}(x)=\int_{S} \phi_{j}(y) G_{i j}(x, y) \mathrm{d} S_{y}, \\
& t_{i}(x)=\int_{S} \phi_{j}(y) T_{i j}(x, y) \mathrm{d} S_{y},
\end{aligned}
$$

where $G_{i j}(x, y)$ and $T_{i j}(x, y)$ represent Green's functions of displacement and traction, respectively, and $\phi_{j}(y)$ can be regarded as the load density at $y$ in the $j$ direction on the boundary surface. The potential function is defined as follows:

$$
f(q, r)=\frac{e^{-i q r}}{r}
$$

where $q$ is a given constant ( $h$ is the compressional wave number, and $k$ is the shear wave number) and $r=|x-y|$, in which $x$ and $y$ represent the positions of the field point and the source point, respectively. Green's functions of displacement and stress can be expressed as follows [40]:

$$
\begin{aligned}
G_{i j}(x, y)= & \frac{1}{4 \pi \mu}\left[\frac{1}{k^{2}} \frac{\partial^{2}}{\partial x_{i} \partial x_{j}}(f(k, x, y)-f(h, x, y))+\delta_{i j} f(k, x, y)\right], \\
T_{i j}(x, y)= & \lambda\left(\frac{\partial G_{1 j}}{\partial x_{1}}+\frac{\partial G_{2 j}}{\partial x_{2}}+\frac{\partial G_{3 j}}{\partial x_{3}}\right) n_{i}+\mu\left(\frac{\partial G_{i j}}{\partial x_{1}}+\frac{\partial G_{1 j}}{\partial x_{i}}\right) n_{1} \\
& +\mu\left(\frac{\partial G_{i j}}{\partial x_{2}}+\frac{\partial G_{2 j}}{\partial x_{i}}\right) n_{2}+\mu\left(\frac{\partial G_{i j}}{\partial x_{3}}+\frac{\partial G_{3 j}}{\partial x_{i}}\right) n_{3},
\end{aligned}
$$

where $i, j=1,2,3$ which correspond to the $x, y, z$ direction and $n_{i}$ are the direction cosines of the unit normal vector.

When $x \neq y$, equations (2) and (3) can be calculated directly by the Gauss integral method:

$$
\begin{aligned}
& t_{i}(x)=\phi_{j}(y) T_{i j}(x, y) \int_{S} \mathrm{~d} S_{y}=\phi_{j}(y) T_{i j}(x, y) S_{y}, \\
& u_{i}(x)=\phi_{j}(y) G_{i j}(x, y) \int_{S} \mathrm{~d} S_{y}=\phi_{j}(y) G_{i j}(x, y) S_{y}
\end{aligned}
$$




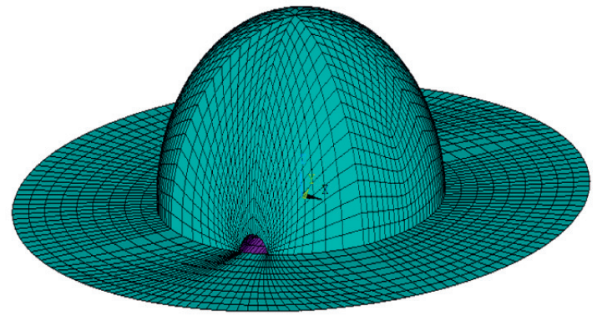

(a)

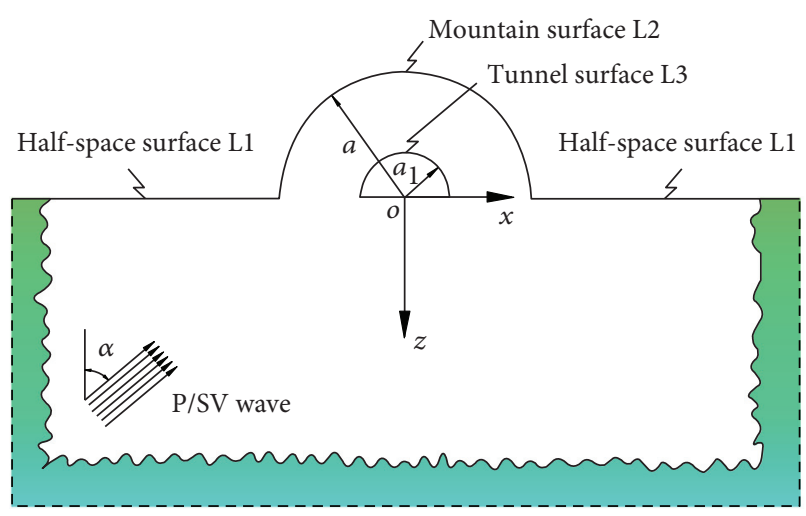

(b)

Figure 1: The physical model of scattering of elastic waves by a 3D tunnel mountain. (a) Surface discretization. (b) Profile perpendicular to the tunnel axis.

where $S_{y}$ is the element area.

When $x=y$, the integrals in equations (2) and (3) are singular. A discrete element is replaced by a disk with identical area, and a virtual uniform load is applied on the disk. Green's function expansion is adopted to solve the problem.

$$
\begin{aligned}
t_{i j}\left(x_{n}, y_{n}\right) & =\frac{1}{2} \delta_{i j}, \\
u_{i j}\left(x_{n}, y_{n}\right) & =\frac{\left[F_{1} \delta_{i j}+F_{2} n_{i} n_{j}\right]}{4 \mu}, \\
F_{1} & =\frac{\left(f\left(h, R_{e}\right)-f\left(k, R_{e}\right)\right)}{k^{2}}+\frac{\left(i h f\left(h, R_{e}\right)+i k f\left(k, R_{e}\right)\right) R_{e}}{k^{2}}-\frac{i 2}{k}, \\
F_{2} & =-3 F_{1}+i 2 h R_{e} \frac{\left(f\left(h, R_{e}\right)-1\right)}{k^{2}}+i 4 R_{e} \frac{\left(f\left(k, R_{e}\right)-1\right)}{k},
\end{aligned}
$$

where $R_{e}$ is the radius of equivalent disk of the discrete elements.

3.2. Wave Field Analysis. The total wave field can be composed of the half-space free field and the scattering field. The free field is the wave field of elastic wave incident on the halfspace bedrock. In the half-space, the $\mathrm{P}$ wave and the SV wave with circular frequency $\omega$ are incident at angles $\theta_{\alpha}$ and $\theta_{\beta}$, respectively. The wave potential functions can be expressed as follows:

$$
\begin{aligned}
& \varphi^{(i)}(x, z)=\exp \left[-i h\left(x \sin \theta_{\alpha}-z \cos \theta_{\alpha}\right)\right], \\
& \psi^{(i)}(x, z)=\exp \left[-i k\left(x \sin \theta_{\beta}-z \cos \theta_{\beta}\right)\right] .
\end{aligned}
$$

The incident $\mathrm{P}$ and $\mathrm{SV}$ waves will reflect at the half-space surface, and the reflection wave functions are as follows:

$$
\begin{aligned}
& \varphi^{(r)}(x, z)=A_{2} \exp \left[-i h\left(x \sin \theta_{\alpha}+z \cos \theta_{\alpha}\right)\right] \\
& \psi^{(r)}(x, z)=B_{2} \exp \left[-i k\left(x \sin \theta_{\beta}+z \cos \theta_{\beta}\right)\right],
\end{aligned}
$$

where the reflection coefficients $A_{2}$ and $B_{2}$ were given in the literature [39]. $h$ and $k$ are the wavenumbers of the compressional wave and the shear wave, respectively.

According to the Huygens principle, the scattering field is generated by applying three orthogonal virtual uniform loads on the surface free boundaries near both the mountain and the tunnel.

The total wave field is obtained by the superposition of the free field and the scattering field, and it can be expressed as follows:

$$
\begin{aligned}
& u_{i}^{(t)}=u_{i}^{(f)}+u_{i}^{(s)}, \quad i=1,2,3, \\
& t_{i}^{(t)}=t_{i}^{(f)}+t_{i}^{(s)}, \quad i=1,2,3 .
\end{aligned}
$$

The three-dimensional horizontal surface L1, the hemispherical mountain surface L2, and the tunnel boundary L3 are all the surface free boundaries, at which the tractions are zero. According to equation (11), the boundary condition can be expressed as follows:

$$
t_{i}^{(s)}+t_{i}^{(f)}=0 .
$$

Substituting equation (3) into equation (12) yields the following equation:

$$
\int_{S} \phi_{j}(y) T_{i j}(x, y) \mathrm{d} S_{y}=-t_{i}^{(f)}(x) .
$$

In order to solve equation (13) numerically, the quadrilateral element is chosen to discretize the mountain surface and the nearby half-space surface. It is assumed that the 
number of discrete elements of the entire free boundaries is $N$, and the virtual uniform loads are applied on each element. For each boundary element with unknown constant load, a system of algebraic equations can be obtained as follows:

$$
\begin{aligned}
\sum_{l=1}^{N} \phi_{j}\left(y_{l}\right) t_{i j}\left(x_{k}, y_{l}\right) & =-t_{i}^{(f)}\left(x_{k}\right), \quad k=1,2, \ldots, N, \\
t_{i j}\left(x_{k}, y_{l}\right) & =\int_{\Delta S_{l}} T_{i j}\left(x_{k}, y\right) \mathrm{d} S_{y} .
\end{aligned}
$$

\section{Validation of the Method}

In order to validate the accuracy and efficiency of the IBE algorithm for the site response analysis, the ratio of tunnel radius to the mountain radius is 0.01 . The numerical results for vertically incident plane $\mathrm{P}$ and SV waves by the IBEM are compared with those of $[40,41]$. The geometry of the $3 \mathrm{D}$ Gaussian shaped mountain with circular plane projection is expressed as follows:

$$
\begin{aligned}
z(x, y) & =a_{z}\left(1-3 \sigma^{2}+2 \sigma^{3}\right), \\
\sigma & =\frac{1}{a} \sqrt{x^{2}+y^{2}}, \quad 0 \leq \sigma \leq 1,
\end{aligned}
$$

where $a_{z}=0.5 a$ is the height of mountain and $a$ is the maximum horizontal dimension of the mountain.

The $\mathrm{P}$ and SV waves are incident along $z$-axis, respectively. The parameters are given as follows: the shear-wave velocity of half-space $c_{s}=400 \mathrm{~m} / \mathrm{s}$, density $\rho=2000 \mathrm{~kg} / \mathrm{m}^{3}$, Poisson's ratio $v=1 / 3$, the viscous damping ratio of material is 0.01 , and the convergence accuracy is 0.001 . The dimensionless frequency is defined as $\eta=2 a / \lambda=\omega a / \pi c_{s}=1.0$, in which $\lambda$ is the wavelength of shear wave.

The displacement amplitude of the mountain surface and the ground surface along $x$-axis $(y=0)$ are shown in Figure 2. It can be seen that the results by the IBEM have quite good agreement with those of $[40,41]$. Therefore, the IBEM used for solving the seismic response of $3 \mathrm{D}$ tunnel mountain is suitable in this paper.

\section{Results of Numerical Analysis}

The 3D model of tunnel mountain is shown in Figure 1. The following parameters will be used for numerical analysis: the mountain radius $a=50 \mathrm{~m}$, the tunnel radius $a_{1}=5 \mathrm{~m}$, Poisson's ratio $v=0.25$, the shear velocity of half-space $c_{\mathrm{s}}=1000 \mathrm{~m} / \mathrm{s}$, the density $\rho=2000 \mathrm{~kg} / \mathrm{m}^{3}$, and the viscous damping coefficient $=0.01$.

5.1. Surface Displacement of the 3D Tunnel Mountain under the Incident $P$ Wave. Figures 3-6 show the displacement amplitude of the mountain surface for the vertically incident
$\mathrm{P}$ wave with individual frequency, respectively. It can be seen that the peak displacements mostly appear on the mountainsides and near the tunnel entrance, and the higher the incidence frequency of wave, the more significant the displacement amplification effect in $y$ direction. When $\eta$ is 0.5 , 1,2 , and 5 , the corresponding peak displacement in $y$ direction is $0.6,2.1,2.2$, and 2.5 (Figures $3(\mathrm{~b}), 4(\mathrm{~b}), 5(\mathrm{~b})$, and $6(\mathrm{~b}))$, respectively. The peak displacement in the principal direction $z$ is different from the ones in the secondary direction, and the maximum displacement appears on the mountain top. When $\eta$ is $0.5,1,2$, and 5 , the peak displacement in the principal direction is $4.3,5.2,4.5$, and 4.2 (see Figures 3(c), 4(c), 5(c), and 6(c)), respectively, and presents the ring distribution. With the increase of the incidence frequency of wave, the focal area of displacement amplification is reduced gradually.

For the case of incident wave with high frequency, the scattered waves interfere strongly with each other, which leads to the multiple peaks of displacement in the principal direction; for example, for $\eta=5$, this phenomenon can be seen obviously in Figure 6(c). However, no analogous phenomenon occurs for the incident wave with lower frequency; as for the case in $z$ direction, the only single peak displacement appears in the middle, and the values decrease gradually from the middle to the surrounding. As can be seen in Figure 3(c), no obvious interference occurs for $\eta=0.5$.

The surface displacement amplitudes of the $3 \mathrm{D}$ tunnel mountain for the incident $\mathrm{P}$ wave at $30^{\circ}$ are shown in Figures $7(\mathrm{a})-7(\mathrm{c})-10(\mathrm{a})-10(\mathrm{c})$. It can be found that the distribution of the peak displacements in $y$ direction is analogous to the one for the vertical incidence of $\mathrm{P}$ wave, and the location of peak displacement in $x$ direction is different from that in the case of vertical incidence; that is, the peak displacements mostly appear on one side of the mountainside and near the tunnel entrance, and the amplification is more significant near the tunnel entrance; for example, for $\eta=0.5$, the peak displacement at the tunnel entrance is 3.1 (see Figure 7(a)), while it is 2.7 for the case of vertical incidence (see Figure 3(a)). Meanwhile, the peak displacement in $z$ direction is not on the mountain top but moves to the side. As shown in Figure 7(c), for the lower frequency incidence $(\eta=0.5)$, the location of single peak in $z$ direction gradually moves from the mountain top (see Figure $3(\mathrm{c})$ ) to the side. As shown in Figure 10(c), analogous to the case of vertical incidence, multiple peaks also appear for the high frequency incidence, which is caused by the interference of scattering waves.

\subsection{Surface Displacement of the 3D Tunnel Mountain under} the Incident SV Wave. Figures 11-14 show the displacement amplitude of the mountain surface for the vertically incident SV wave with individual frequency, respectively. It can be seen that, for the lower frequency incidence, due to the existence of tunnel, the peak displacement of the tunnel 


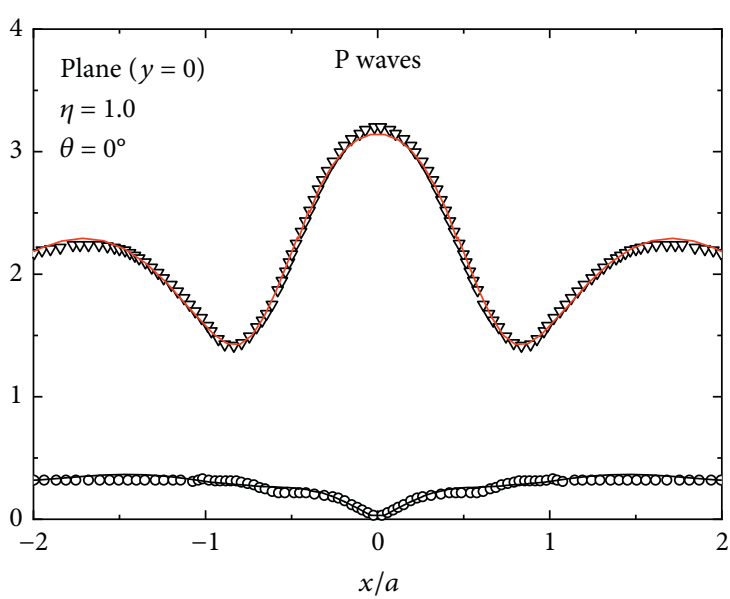

- Present study, $u x$ Present study, $u z$
- Sanchez-Sesma, $u x$

$\nabla$ Sanchez-Sesma, $u z$

(a)

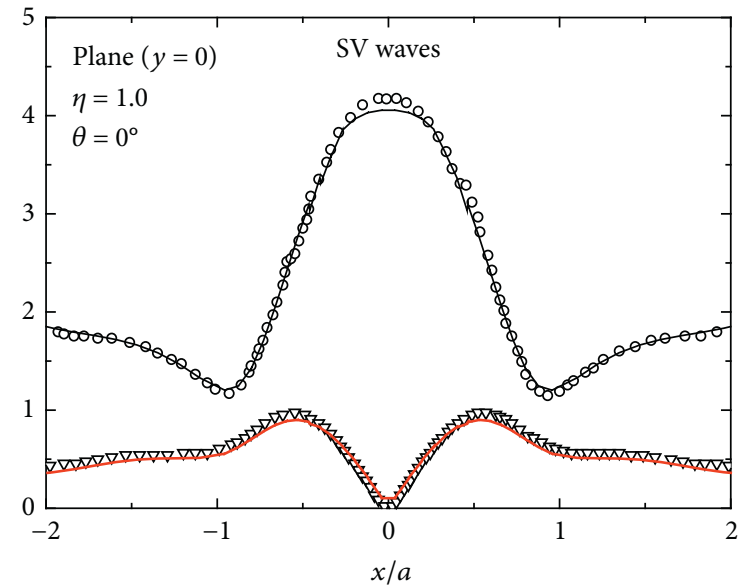

- Present study, $u x \quad \circ$ Sohrabi-Bidar, $u x$ (b)

FIgURE 2: The surface displacement amplitudes of the present study compared with those of [40, 41]. (a) Incident P wave. (b) Incident SV wave.

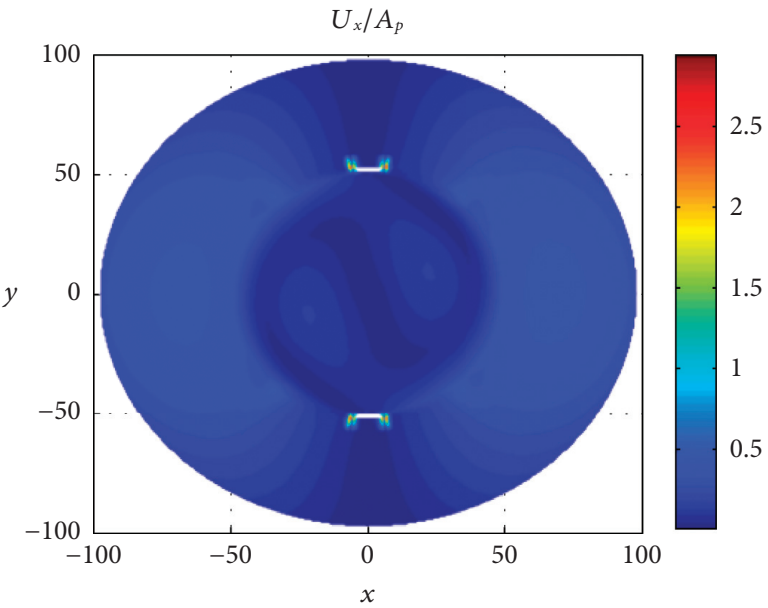

$U_{y} / A_{p}$

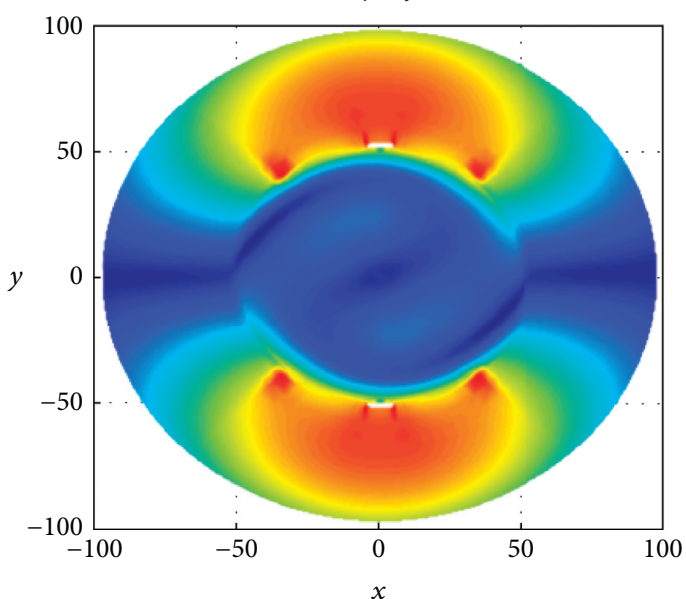

$U_{x} / A_{p}$

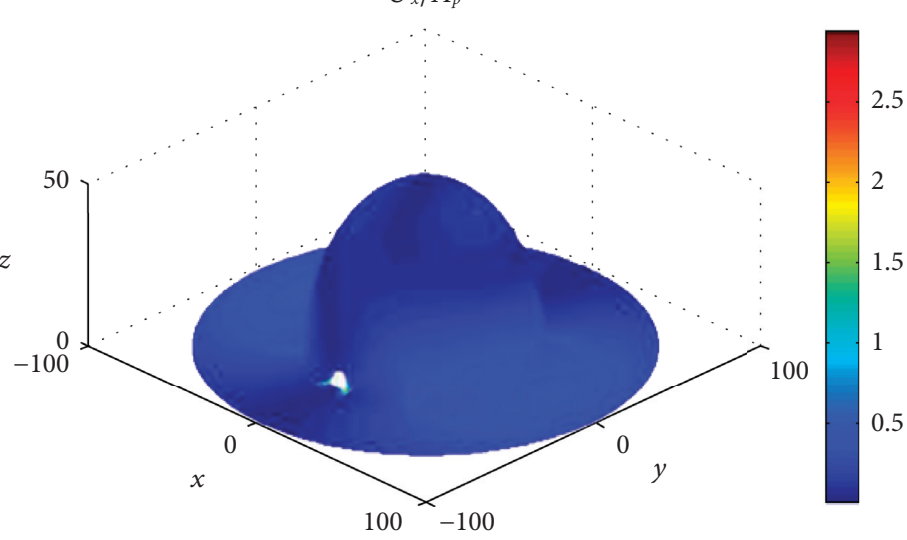

(a)

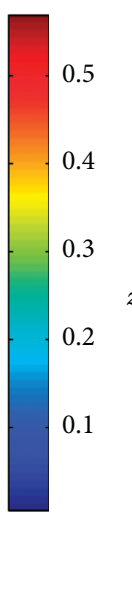

$$
U_{y} / A_{p}
$$

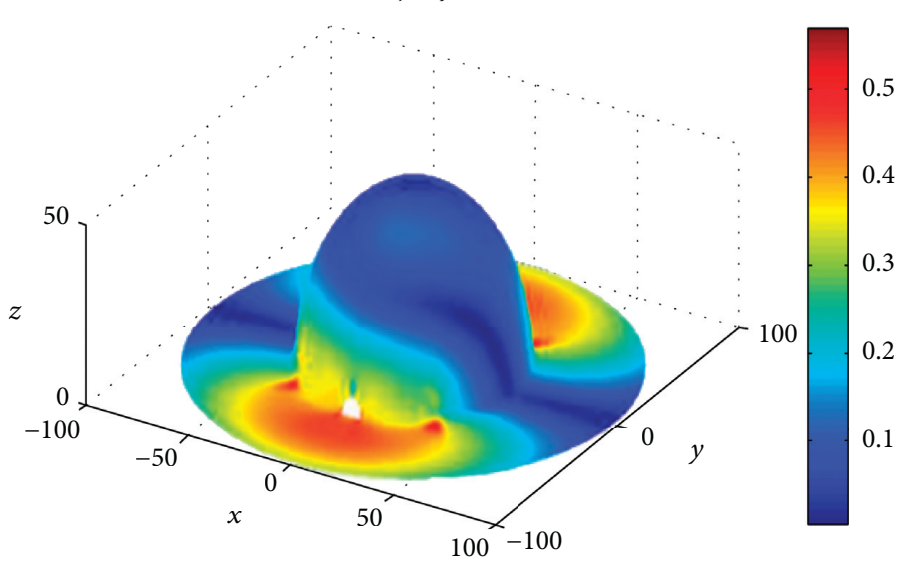

(b)

Figure 3: Continued. 

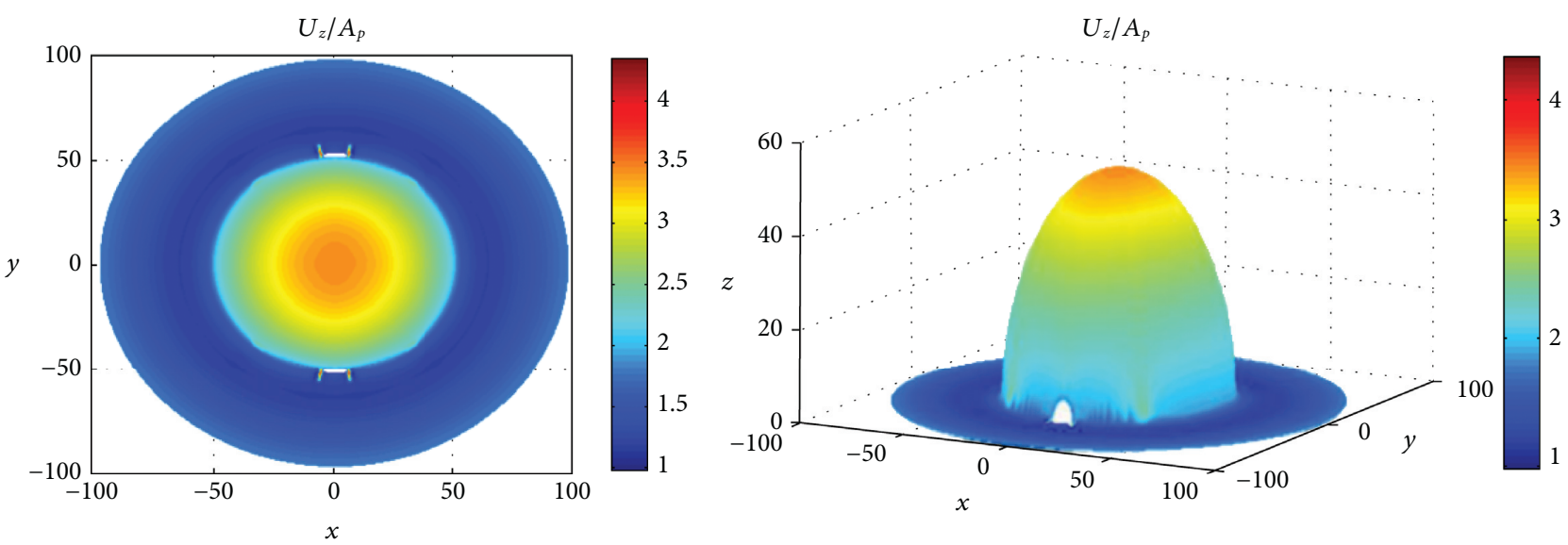

(c)

FIGURE 3: Surface displacement amplitude of the 3D tunnel mountain under the incident $\mathrm{P}$ wave $\left(\eta=0.5, \alpha=0^{\circ}\right)$ : (a) surface displacement amplitude in $x$ direction; (b) surface displacement amplitude in $y$ direction; (c) surface displacement amplitude in $z$ direction.
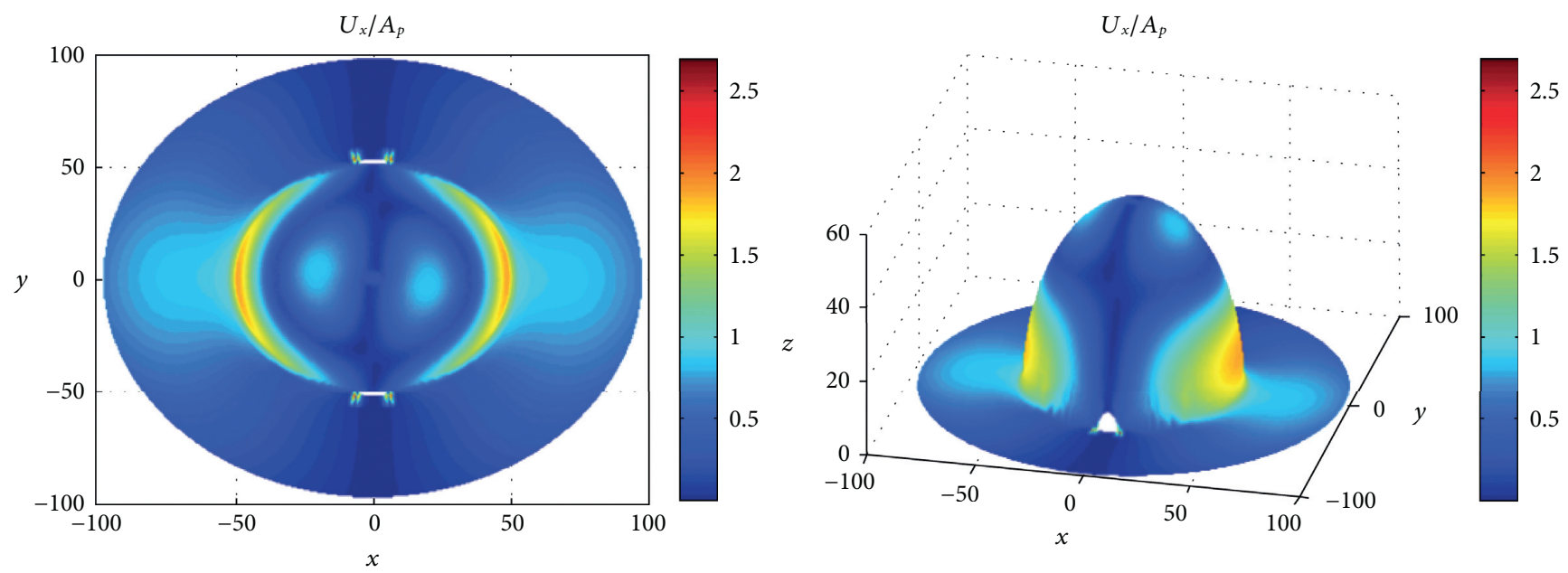

(a)
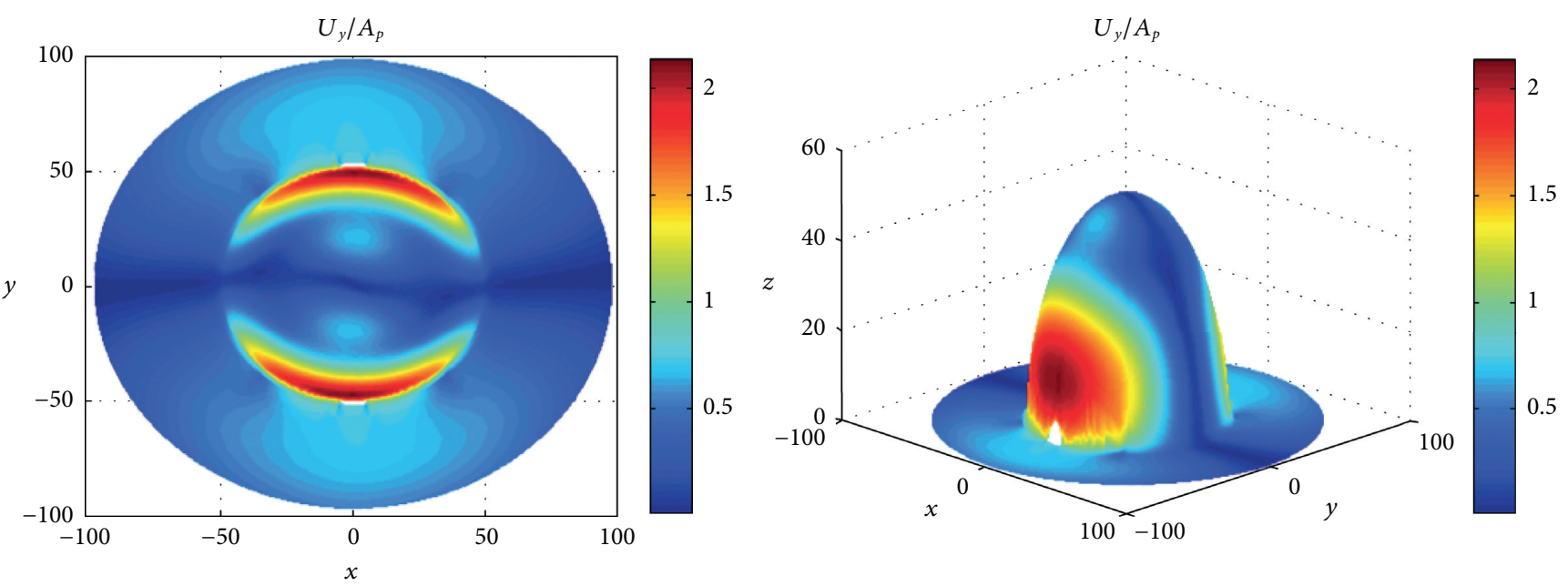

(b)

Figure 4: Continued. 

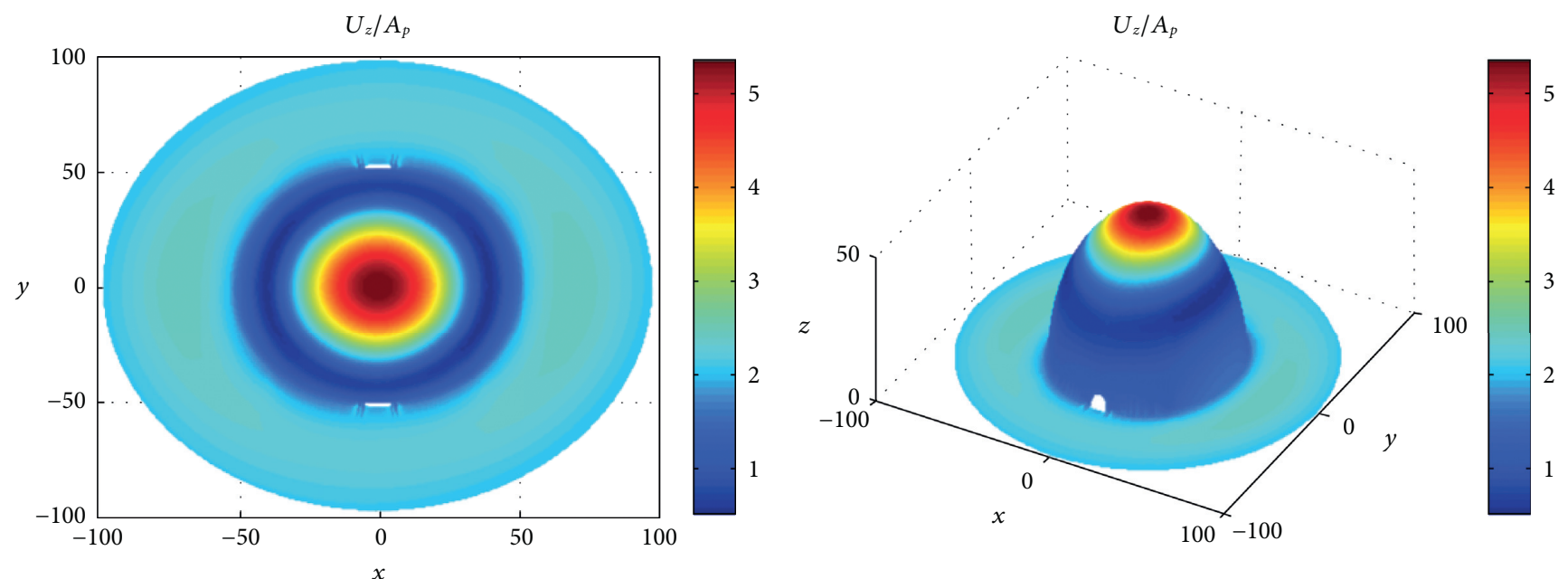

(c)

Figure 4: Surface displacement amplitude of the 3D tunnel mountain under the incident $\mathrm{P}$ wave $\left(\eta=1.0, \alpha=0^{\circ}\right)$ : (a) surface displacement amplitude in $x$ direction; (b) surface displacement amplitude in $y$ direction; (c) surface displacement amplitude in $z$ direction.
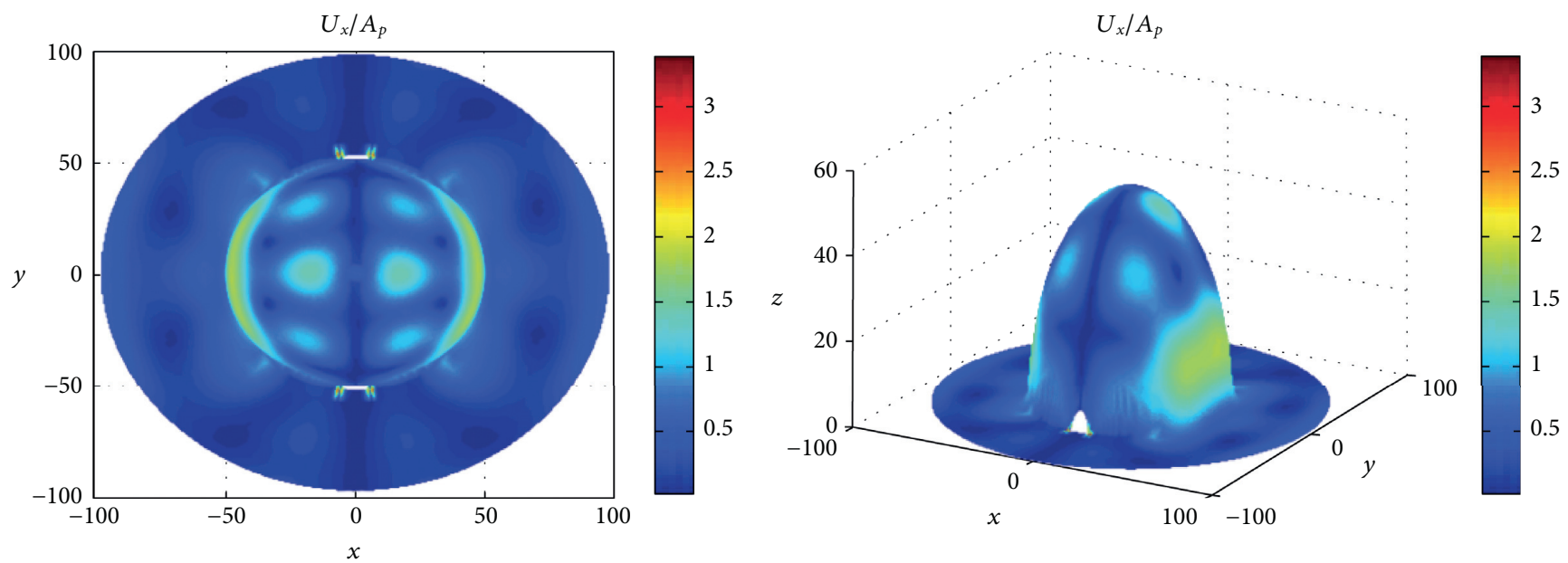

(a)
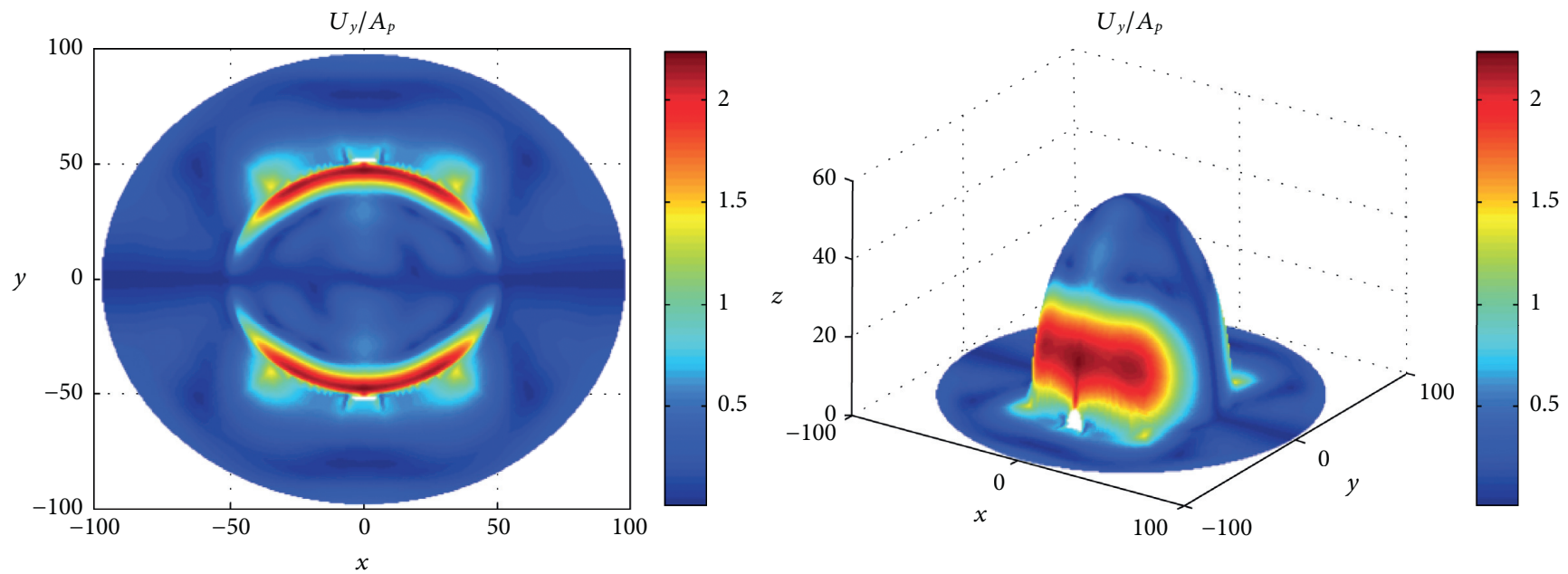

(b)

FIgURE 5: Continued. 

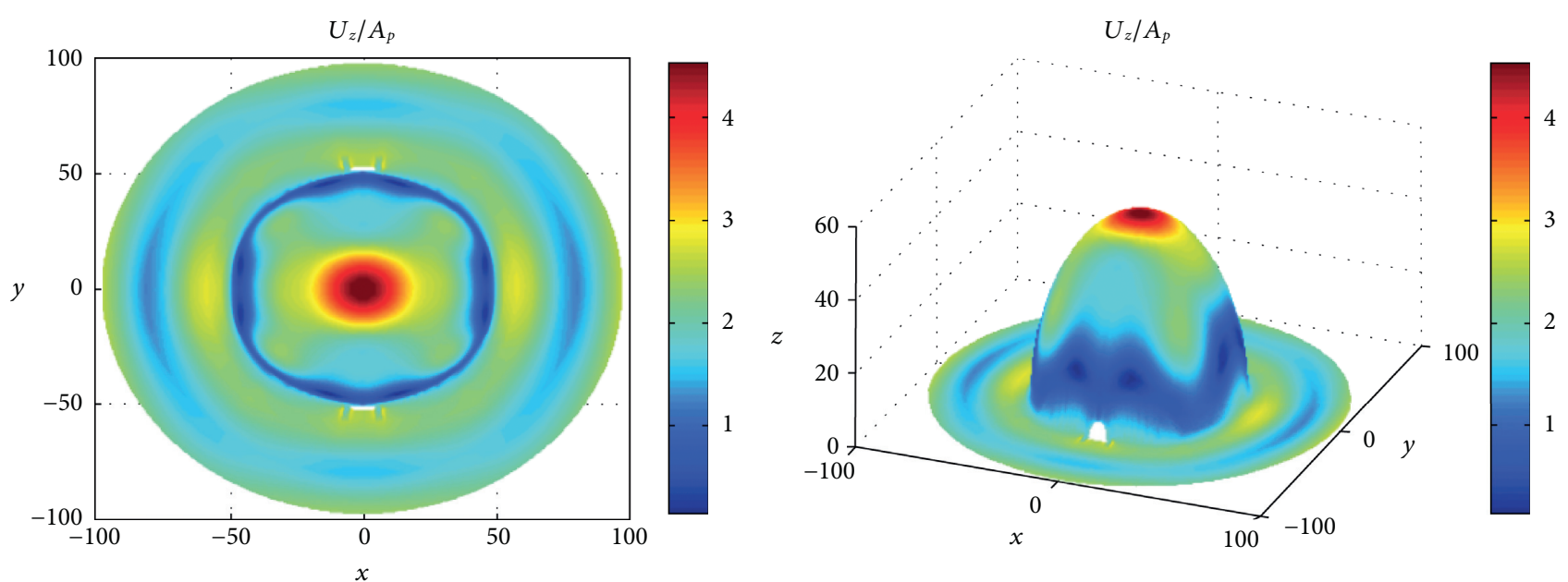

(c)

FIgURE 5: Surface displacement amplitude of the 3D tunnel mountain under the incident $\mathrm{P}$ wave $\left(\eta=2.0, \alpha=0^{\circ}\right)$ : (a) surface displacement amplitude in $x$ direction; (b) surface displacement amplitude in $y$ direction; (c) surface displacement amplitude in $z$ direction.
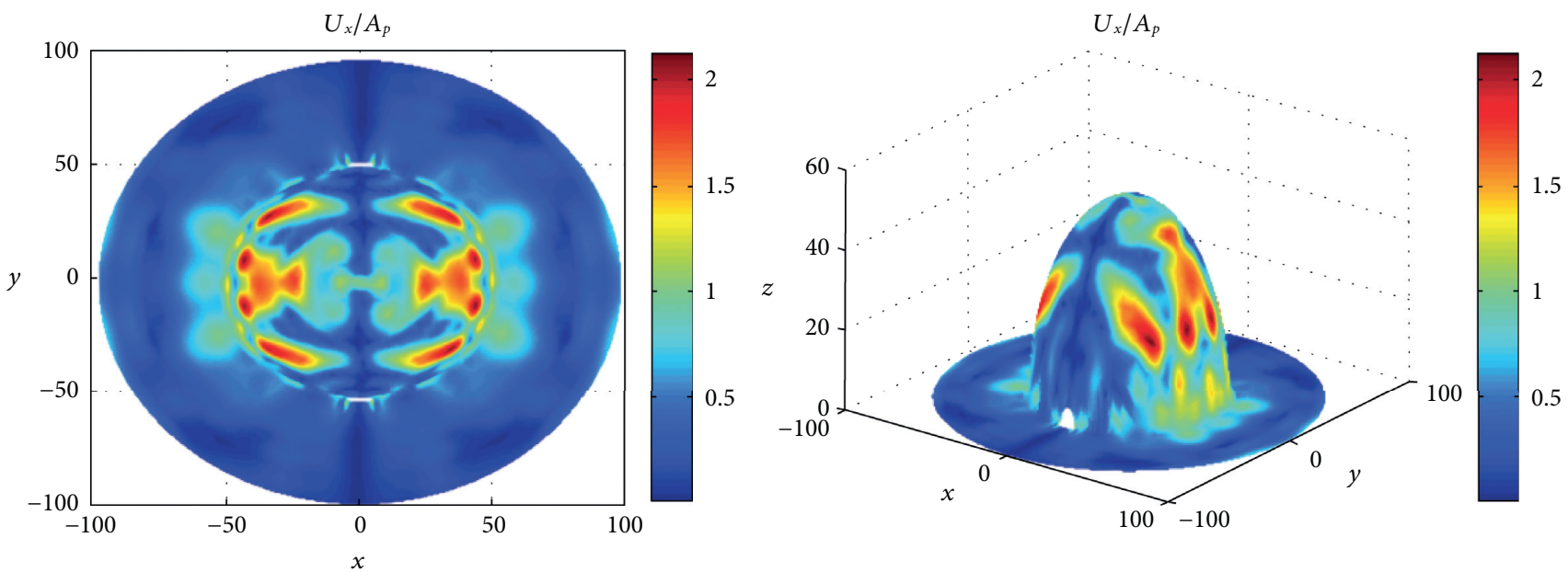

(a)
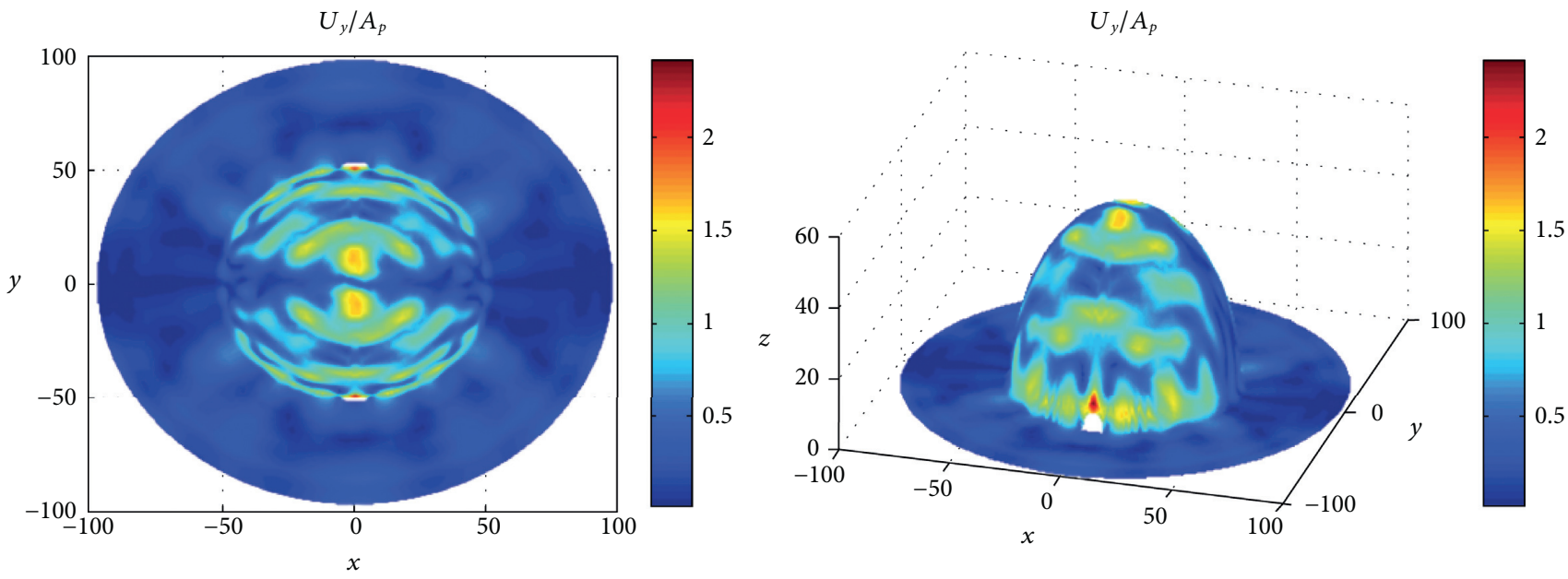

(b)

Figure 6: Continued. 

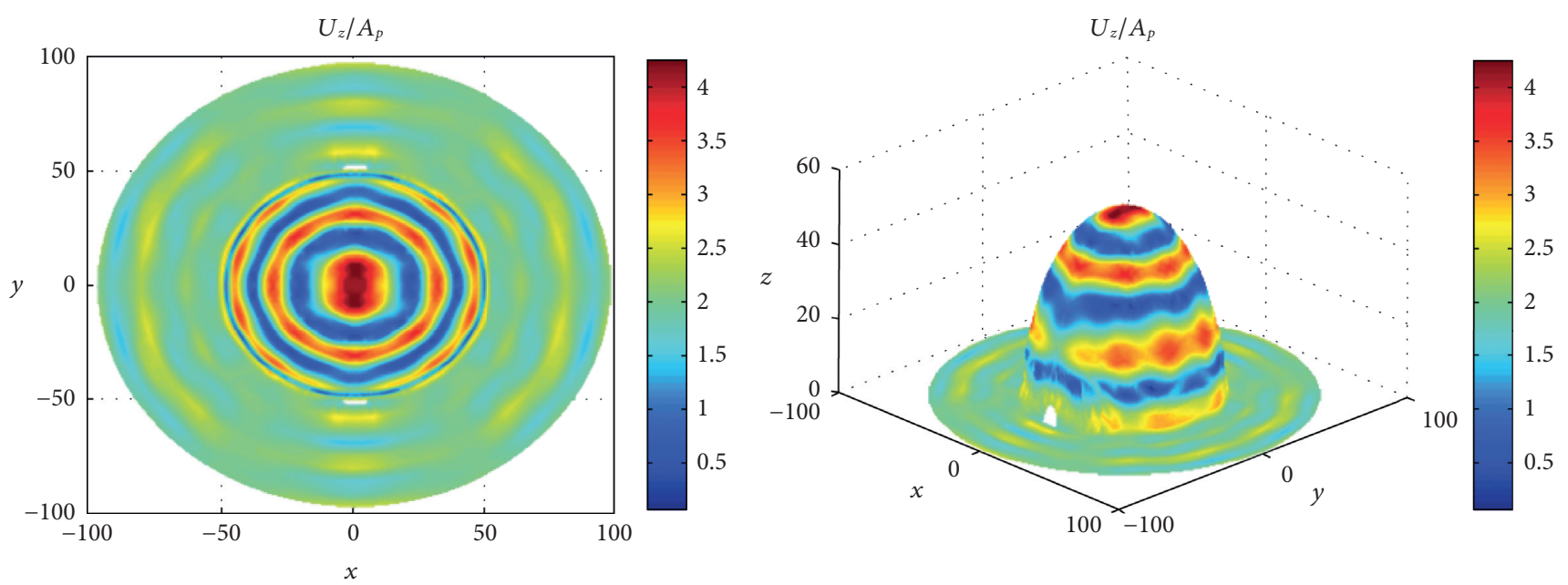

(c)

Figure 6: Surface displacement amplitude of the 3D tunnel mountain under the incident $\mathrm{P}$ wave $\left(\eta=5.0, \alpha=0^{\circ}\right)$ : (a) surface displacement amplitude in $x$ direction; (b) surface displacement amplitude in $y$ direction; (c) surface displacement amplitude in $z$ direction.
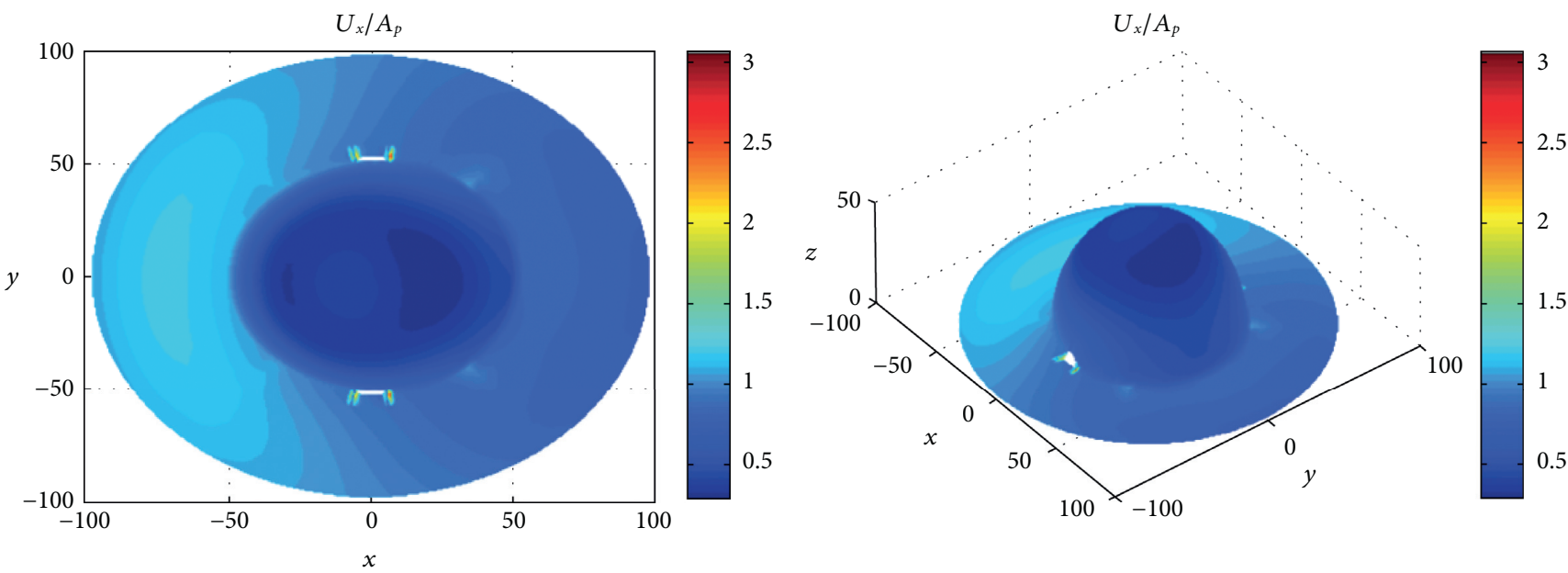

(a)
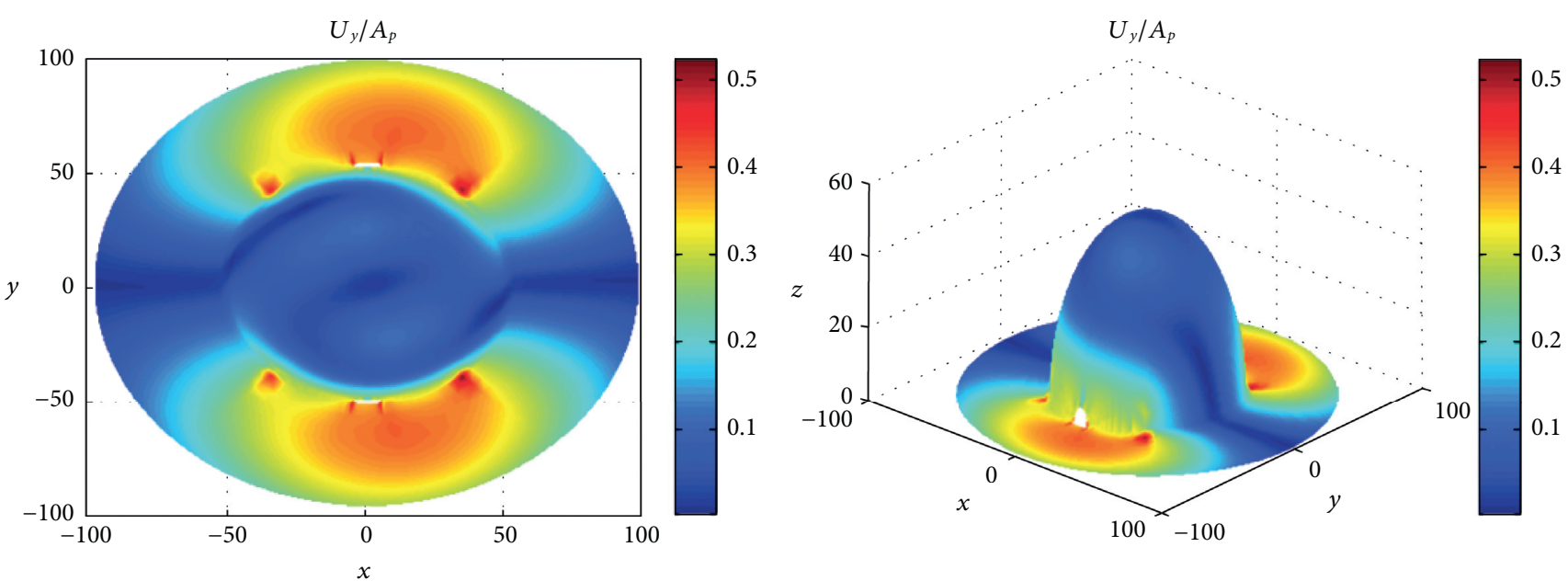

(b)

Figure 7: Continued. 

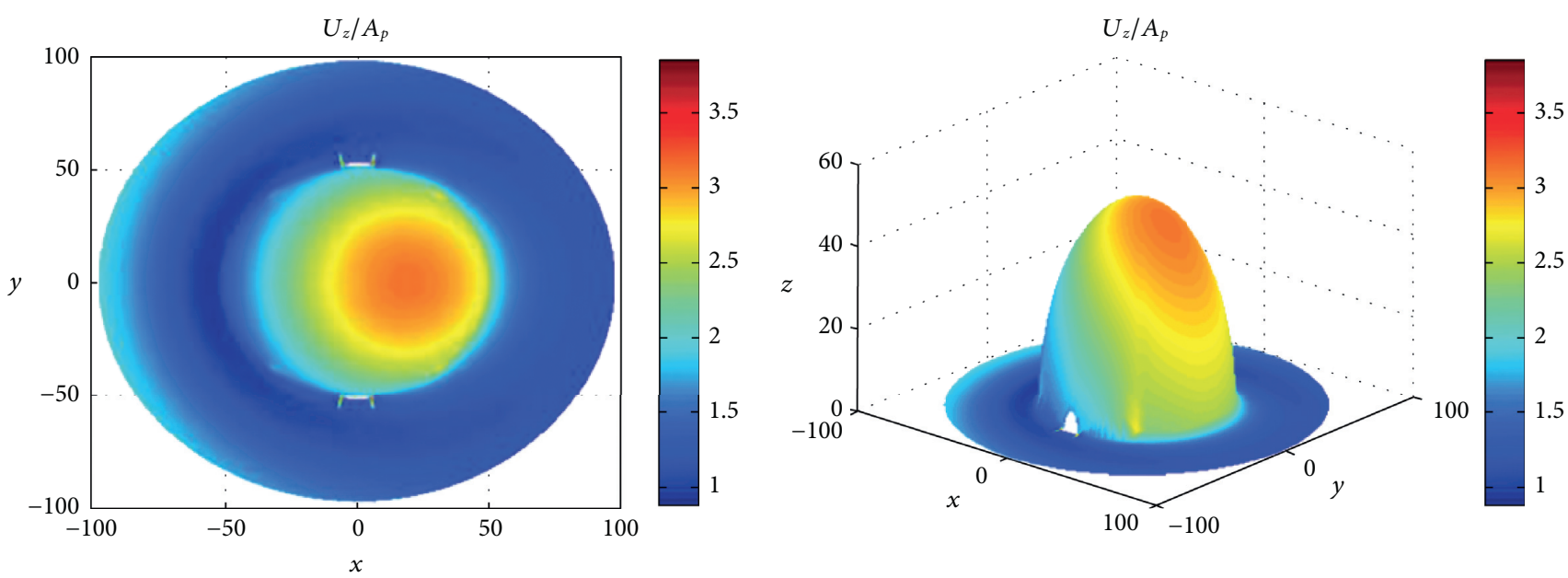

(c)

Figure 7: Surface displacement amplitude of the 3D tunnel mountain under the incident $\mathrm{P}$ wave $\left(\eta=0.5, \alpha=30^{\circ}\right)$ : (a) surface displacement amplitude in $x$ direction; (b) surface displacement amplitude in $y$ direction; (c) surface displacement amplitude in $z$ direction.
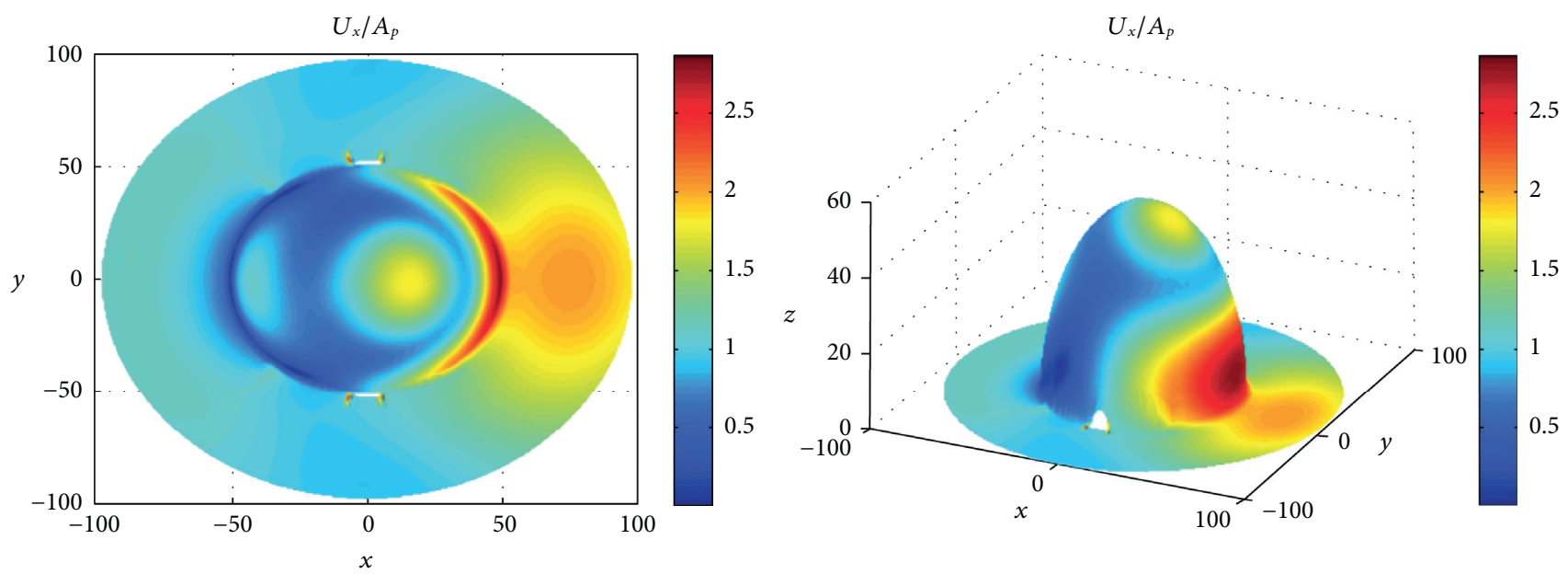

(a)
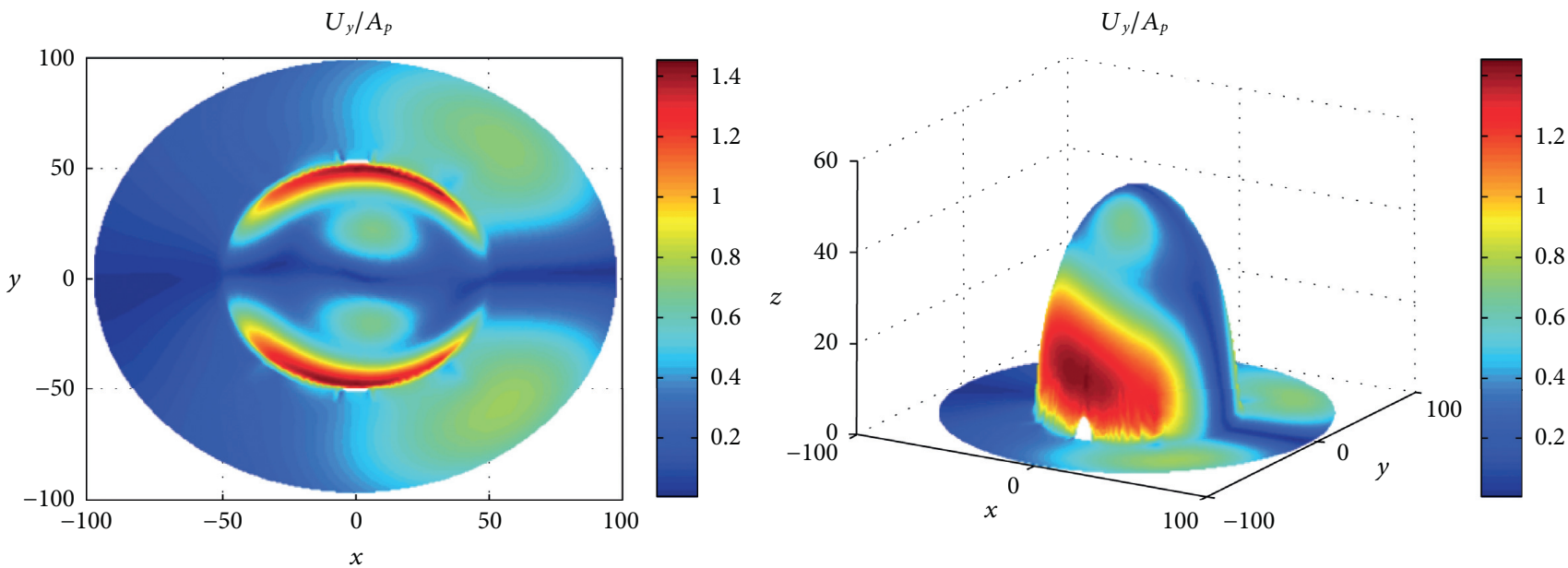

(b)

Figure 8: Continued. 

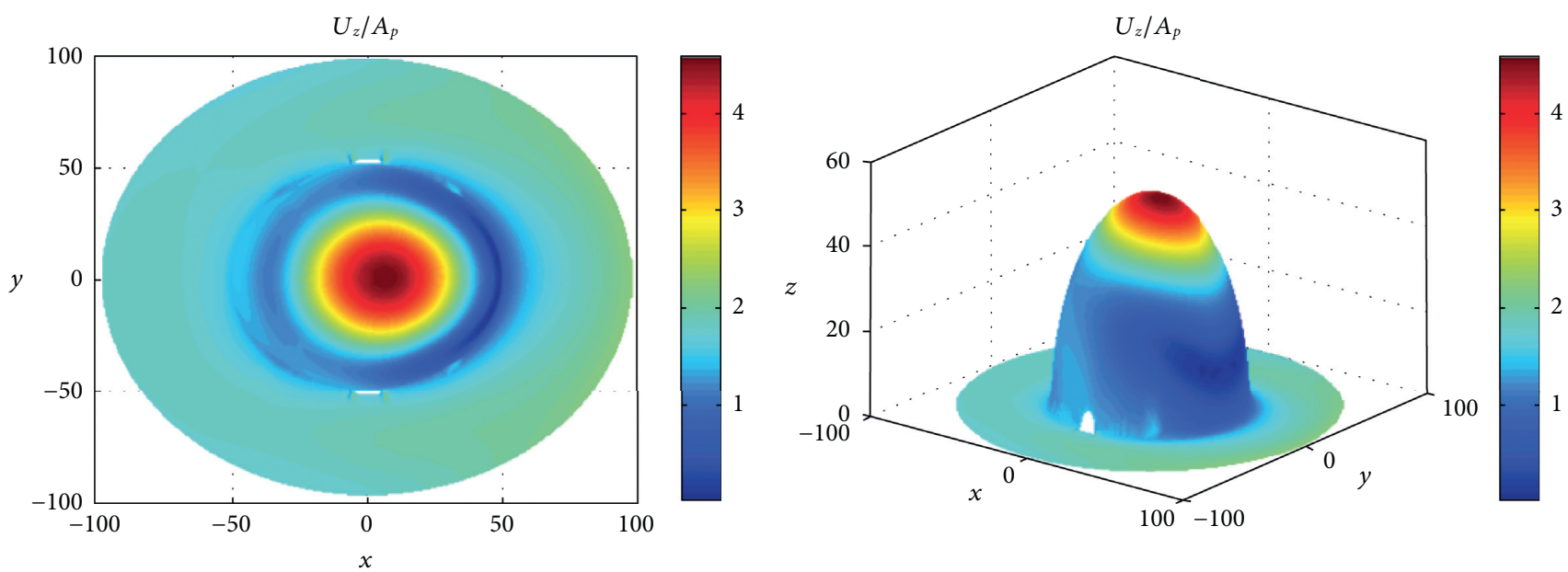

(c)

Figure 8: Surface displacement amplitude of the 3D tunnel mountain under the incident $\mathrm{P}$ wave $\left(\eta=1.0, \alpha=30^{\circ}\right)$ : (a) surface displacement amplitude in $x$ direction; (b) surface displacement amplitude in $y$ direction; (c) surface displacement amplitude in $z$ direction.
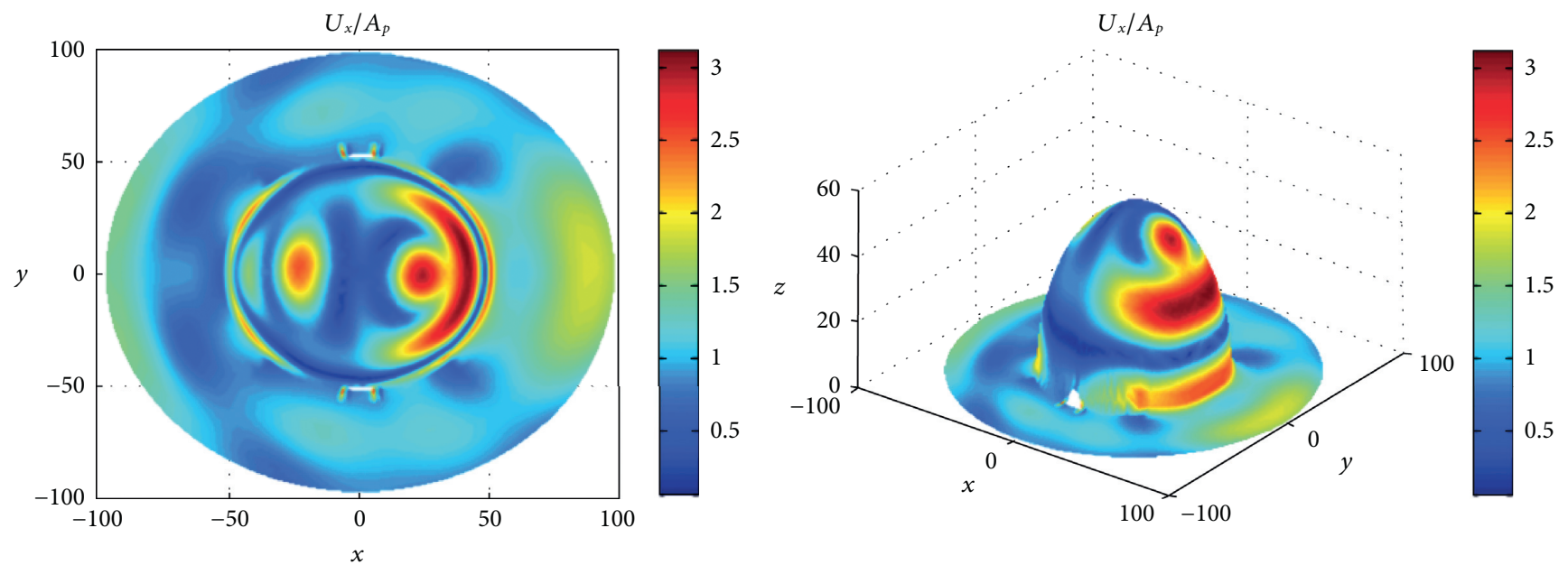

(a)
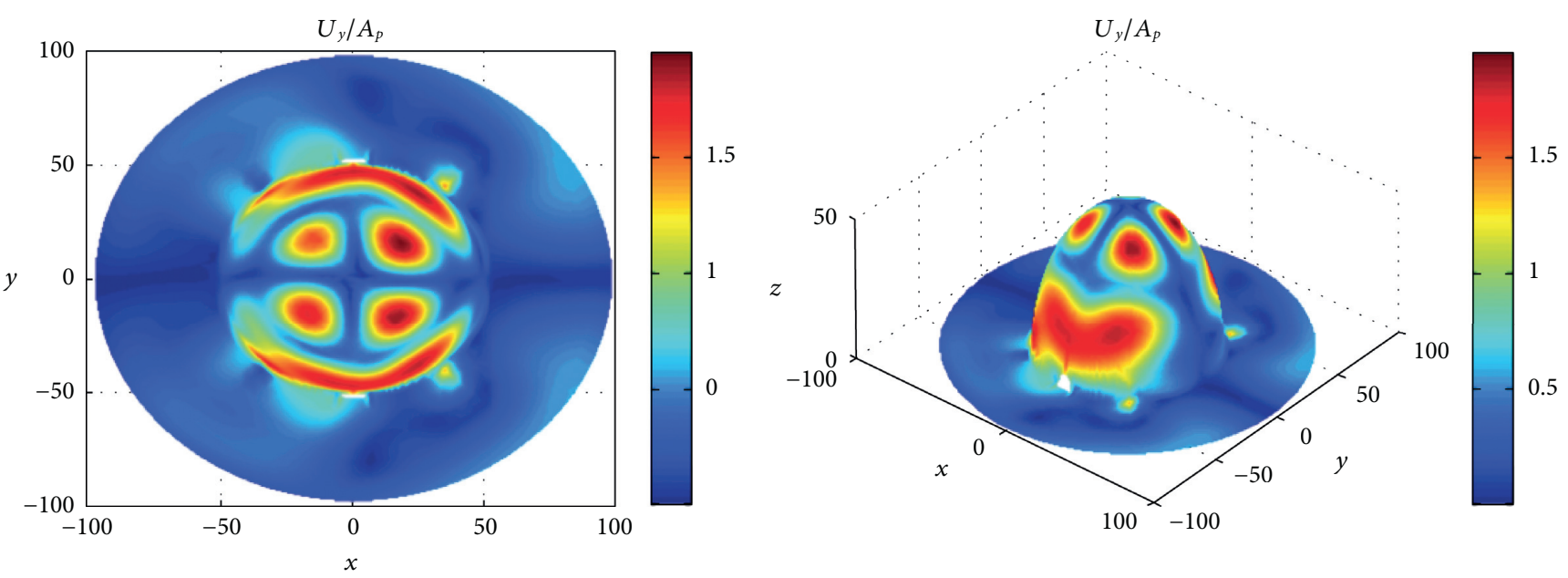

(b)

FIgURE 9: Continued. 

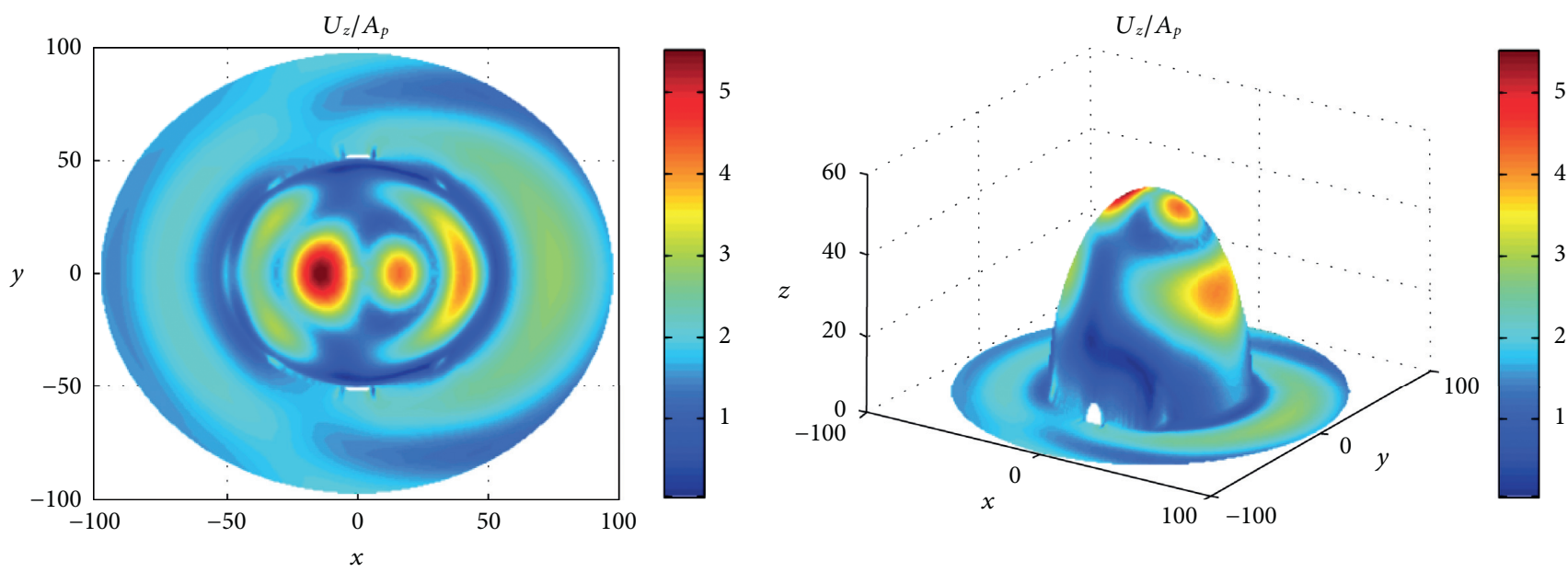

(c)

FiguRE 9: Surface displacement amplitude of the 3D tunnel mountain under the incident $\mathrm{P}$ wave $\left(\eta=2.0, \alpha=30^{\circ}\right)$ : (a) surface displacement amplitude in $x$ direction; (b) surface displacement amplitude in $y$ direction; (c) surface displacement amplitude in $z$ direction.
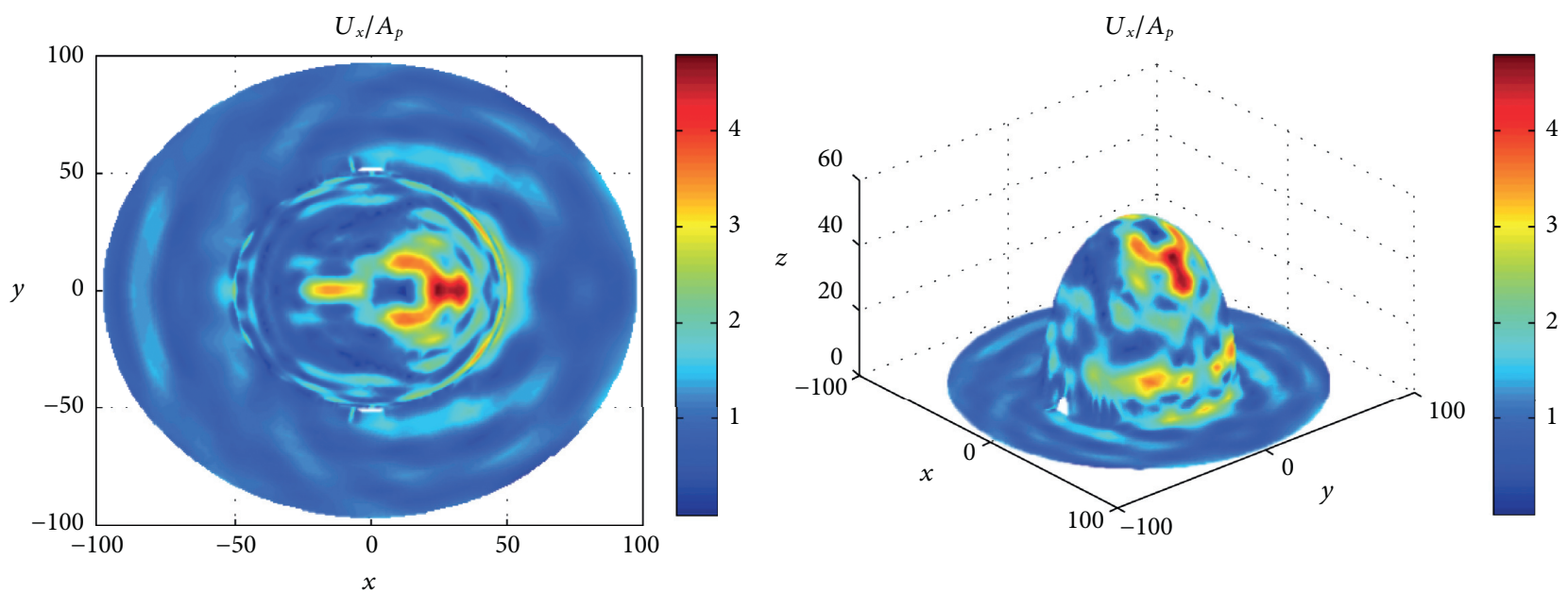

(a)
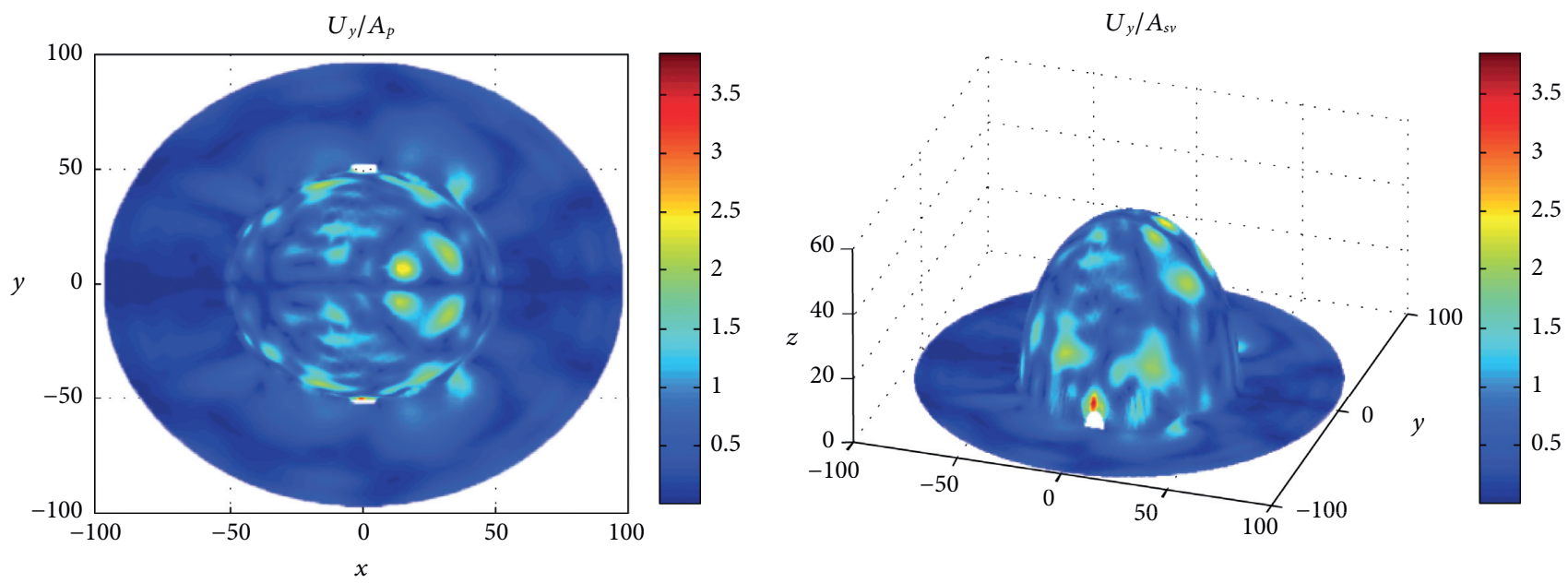

(b)

FIGURE 10: Continued. 

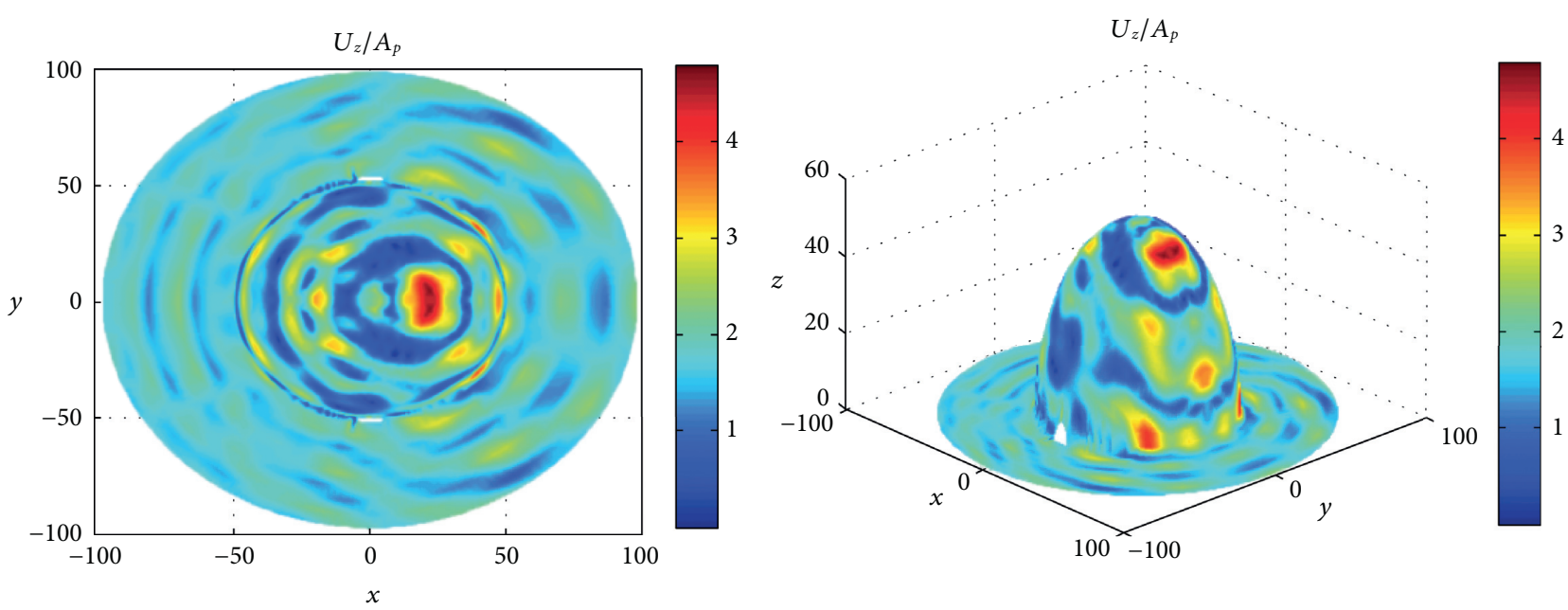

(c)

Figure 10: Surface displacement amplitude of the 3D tunnel mountain under the incident $\mathrm{P}$ wave $\left(\eta=5.0, \alpha=30^{\circ}\right)$ : (a) surface displacement amplitude in $x$ direction; (b) surface displacement amplitude in $y$ direction; (c) surface displacement amplitude in $z$ direction.
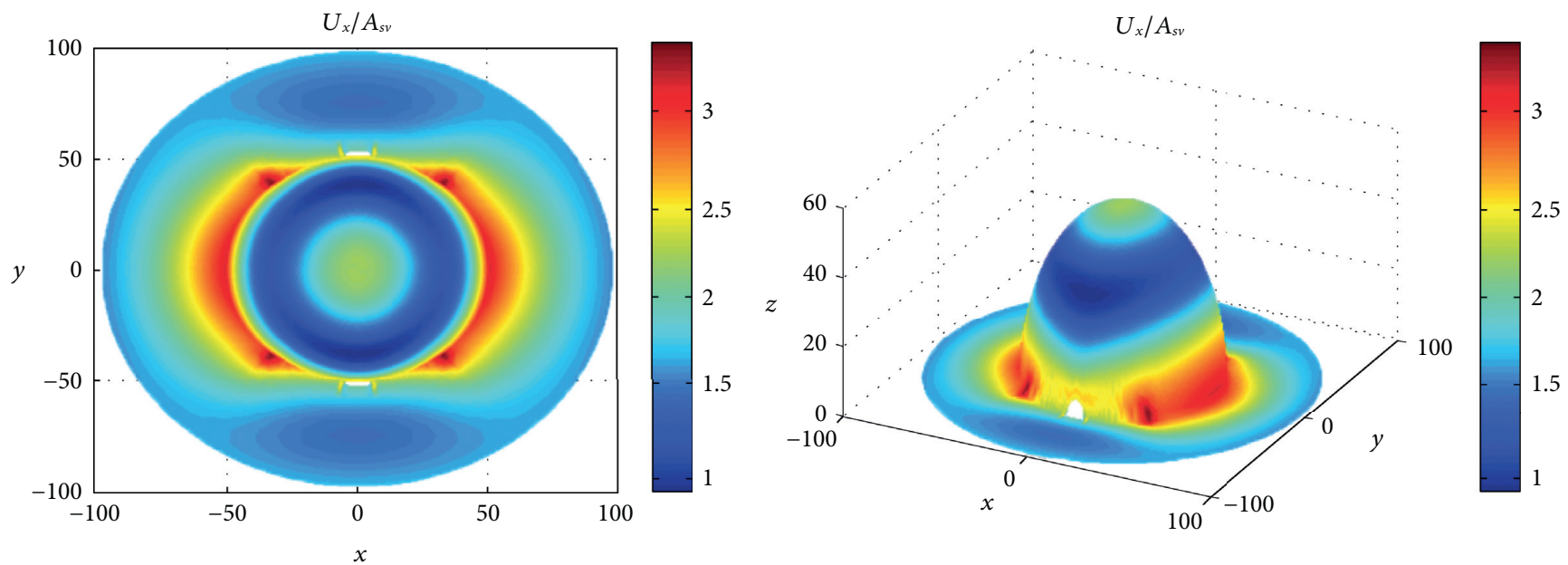

(a)
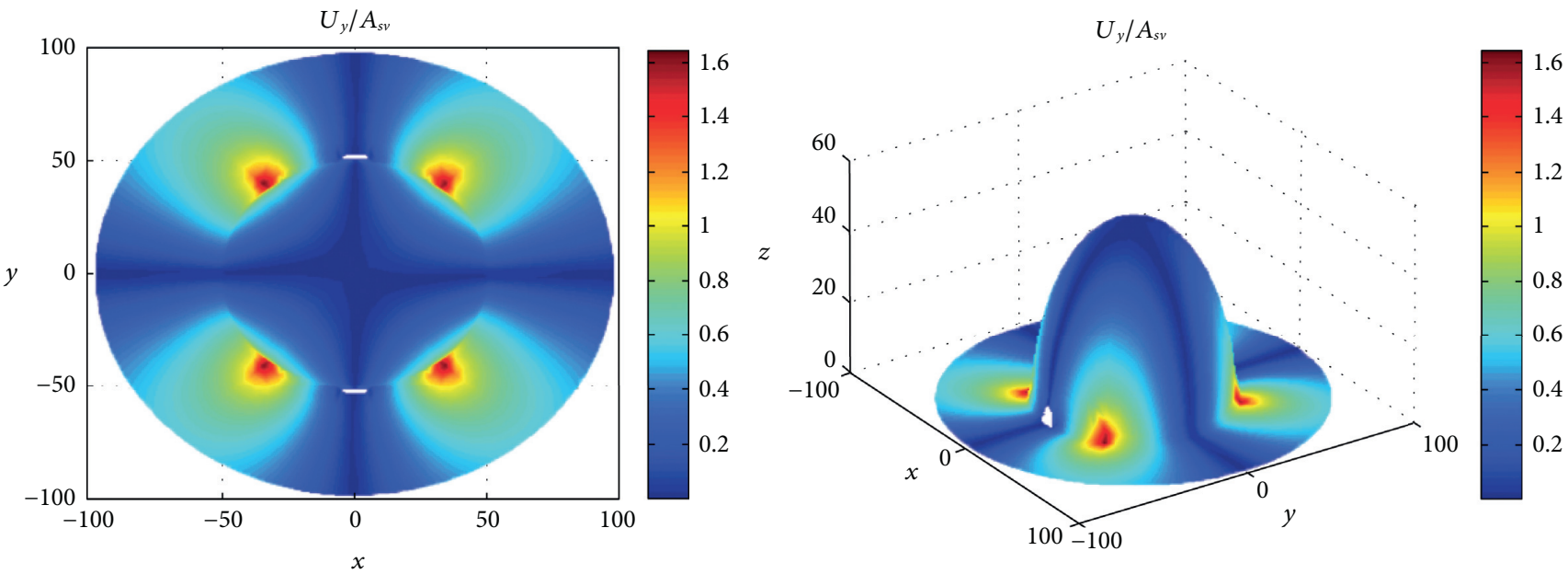

(b)

FIgURE 11: Continued. 

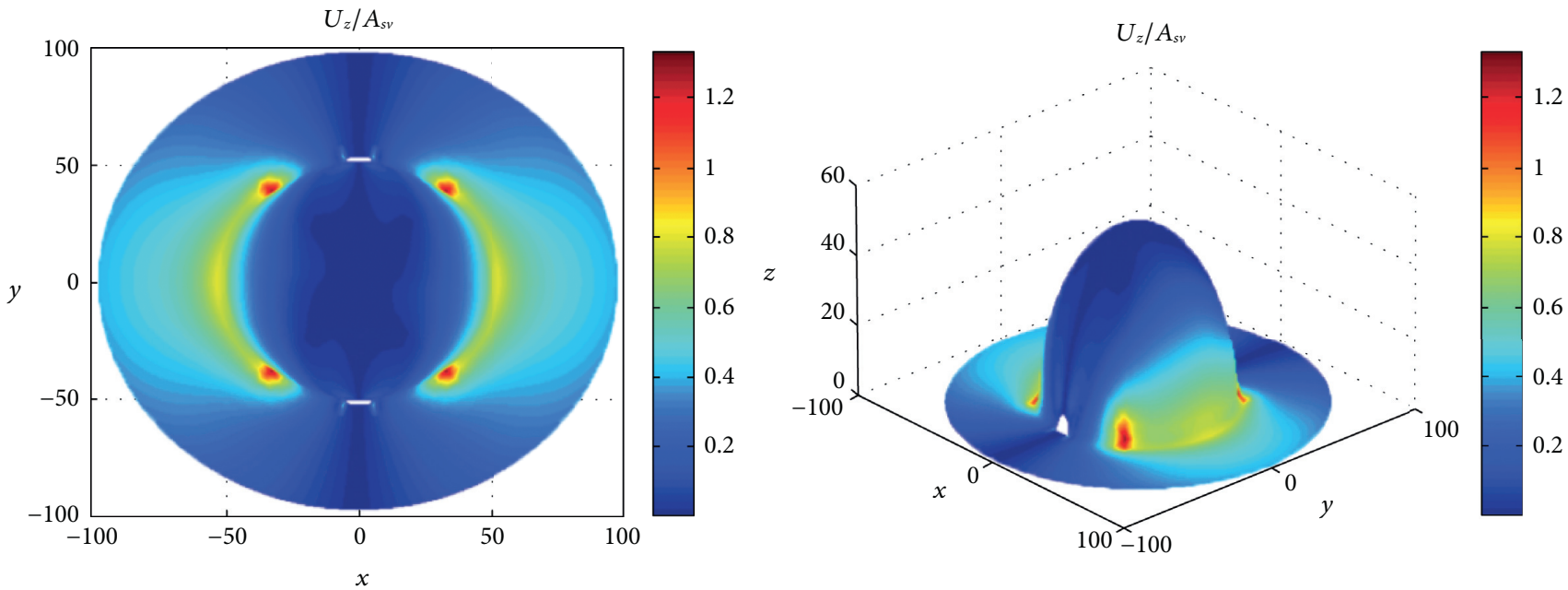

(c)

Figure 11: Surface displacement amplitude of the 3D tunnel mountain under the incident SV wave $\left(\eta=0.5, \alpha=0^{\circ}\right)$ : (a) surface displacement amplitude in $x$ direction; (b) surface displacement amplitude in $y$ direction; (c) surface displacement amplitude in $z$ direction.
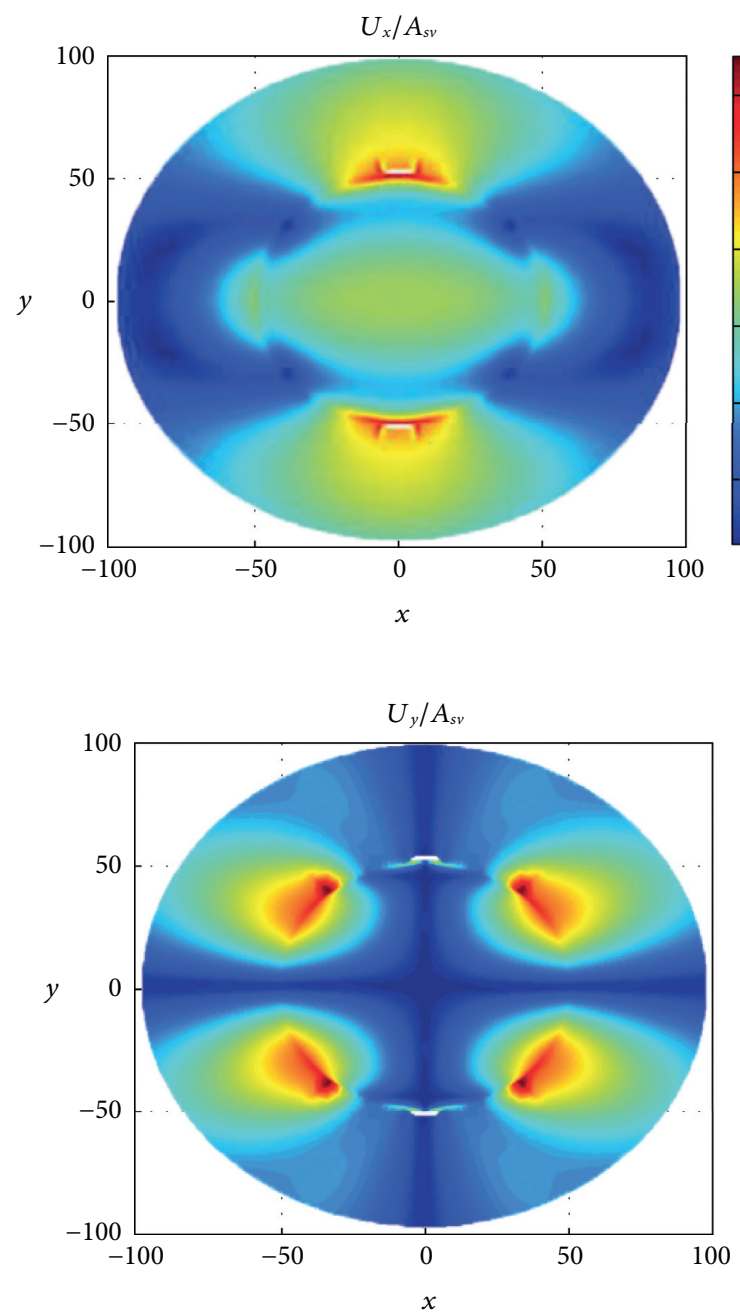
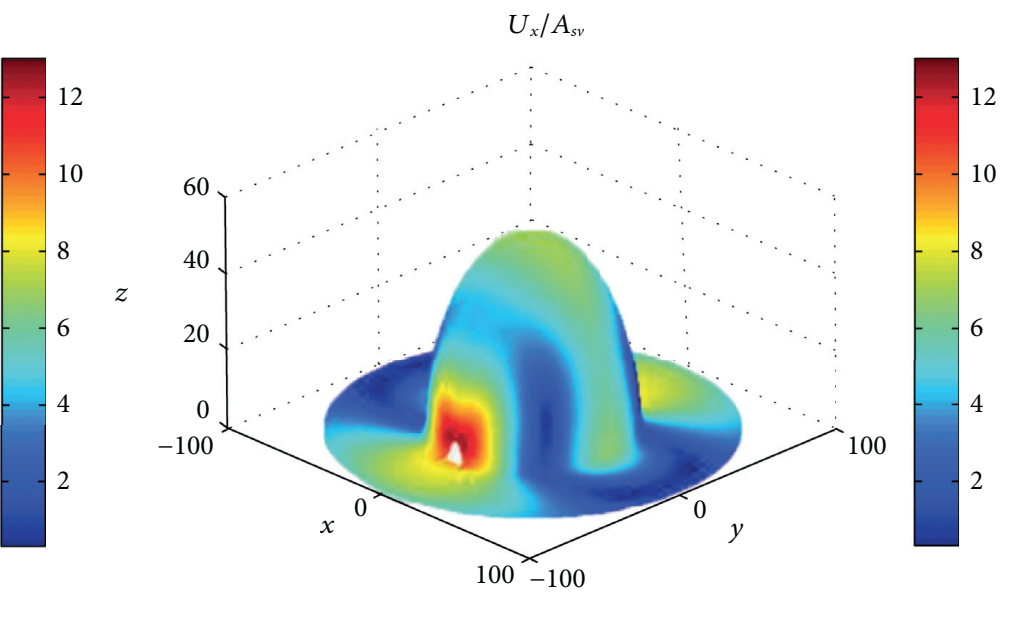

(a)
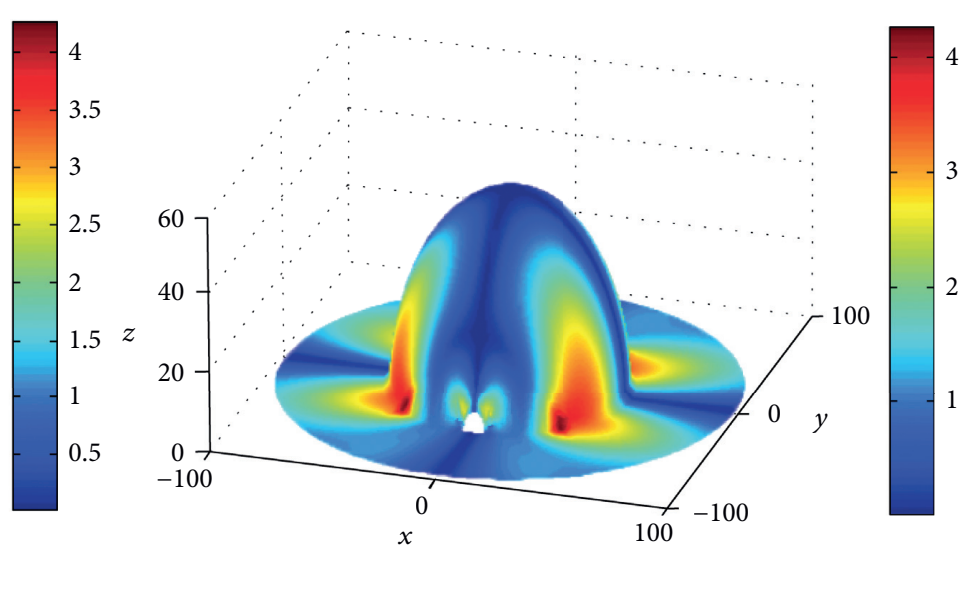

(b)

Figure 12: Continued. 

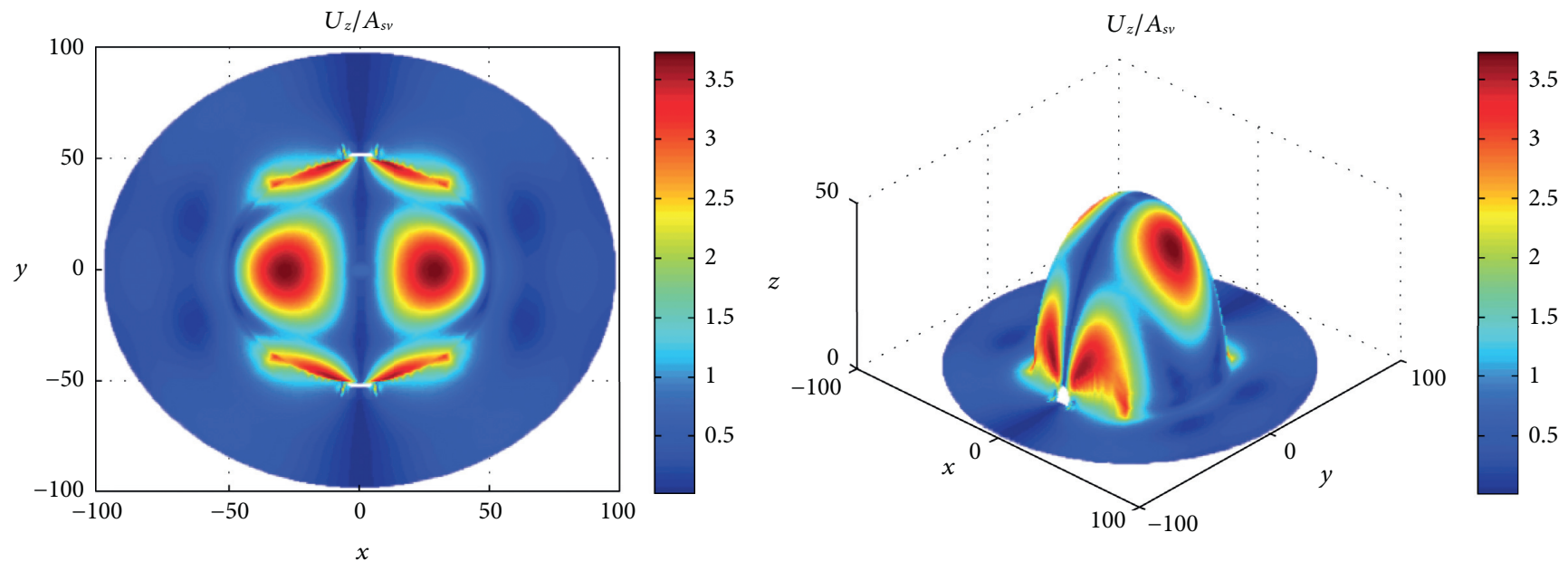

(c)

Figure 12: Surface displacement amplitude of the 3D tunnel mountain under the incident SV wave $\left(\eta=1.0, \alpha=0^{\circ}\right)$ : (a) surface displacement amplitude in $x$ direction; (b) surface displacement amplitude in $y$ direction; (c) surface displacement amplitude in $z$ direction.
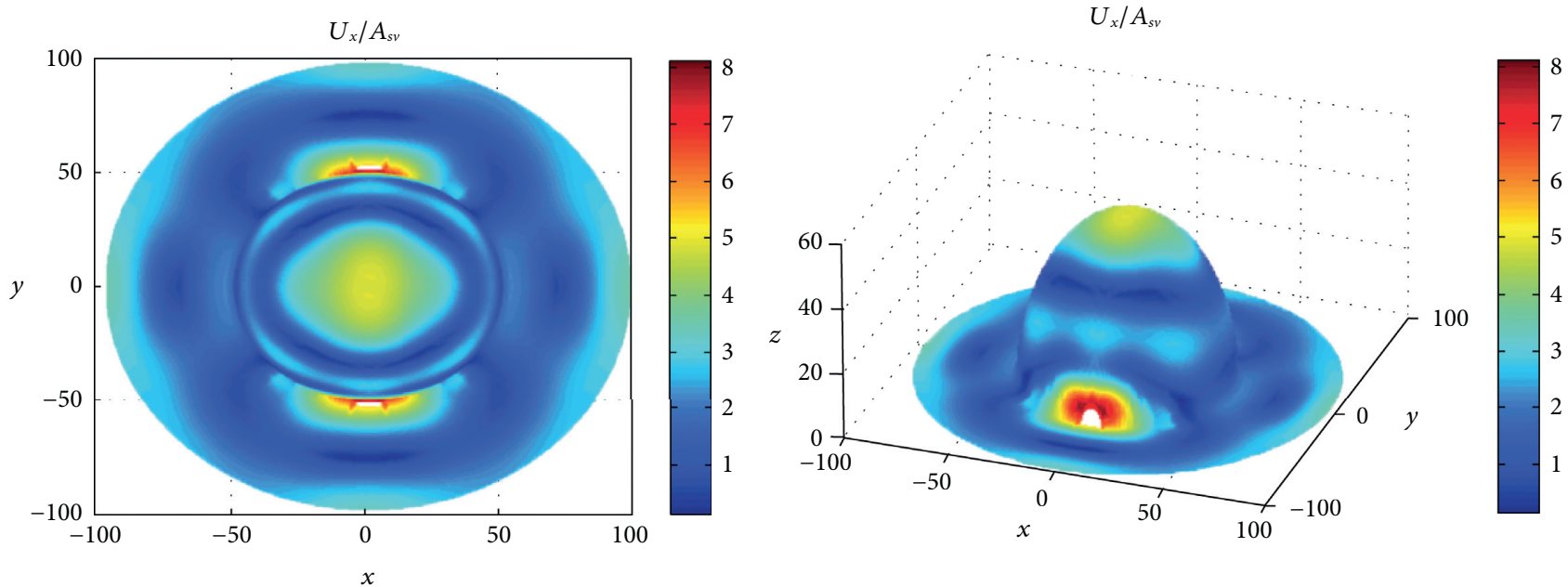

(a)
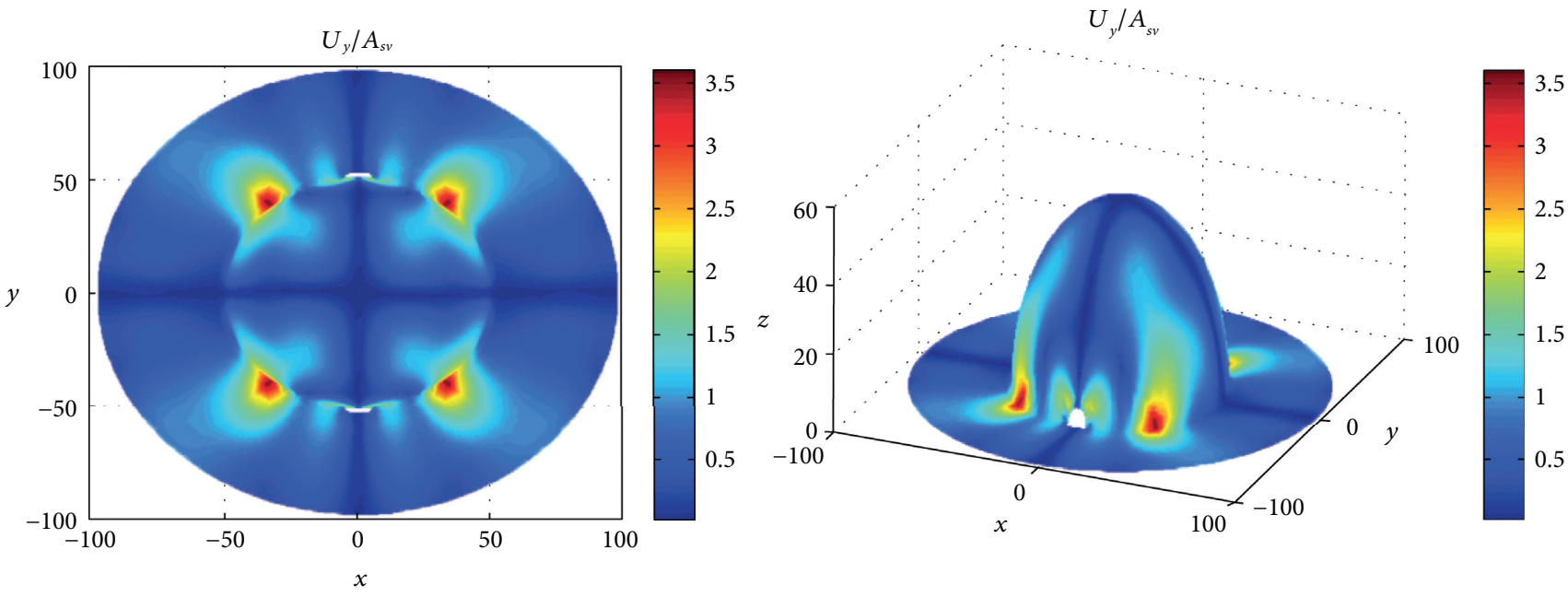

(b)

Figure 13: Continued. 

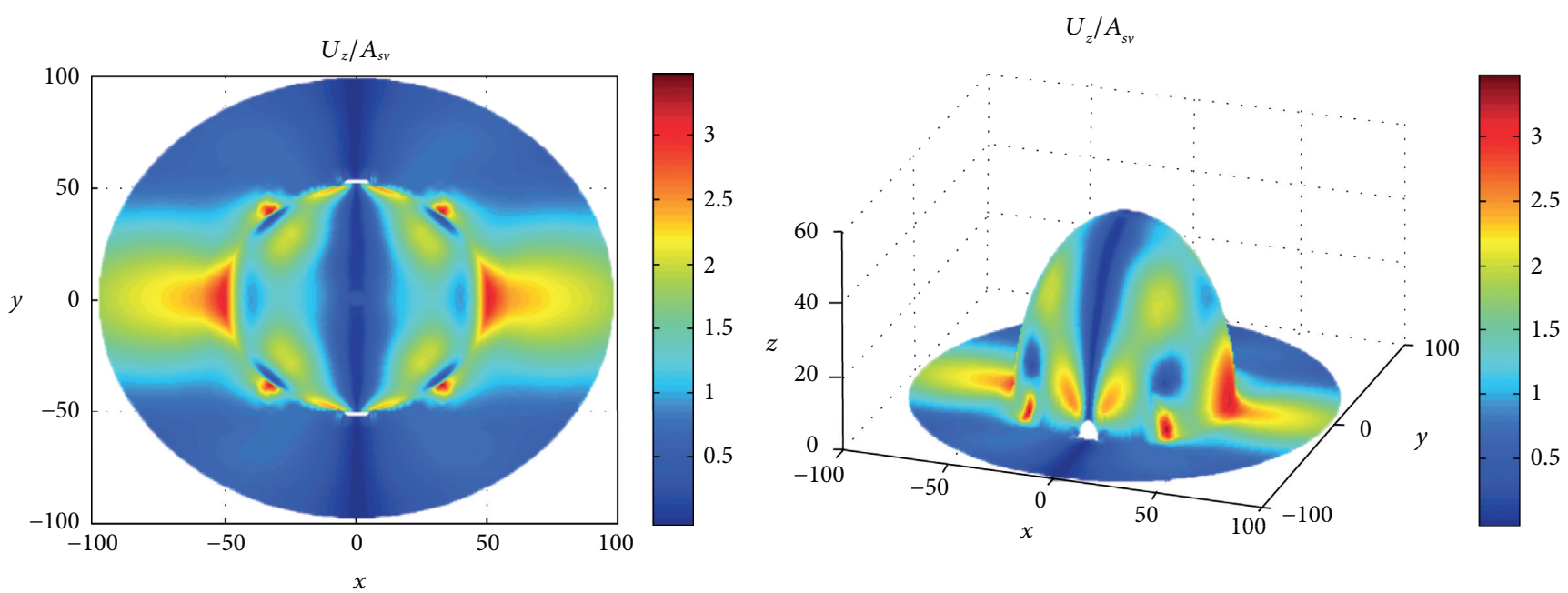

(c)

FIGURE 13: Surface displacement amplitude of the 3D tunnel mountain under the incident SV wave $\left(\eta=2.0, \alpha=0^{\circ}\right)$ : (a) surface displacement amplitude in $x$ direction; (b) surface displacement amplitude in $y$ direction; (c) surface displacement amplitude in $z$ direction.
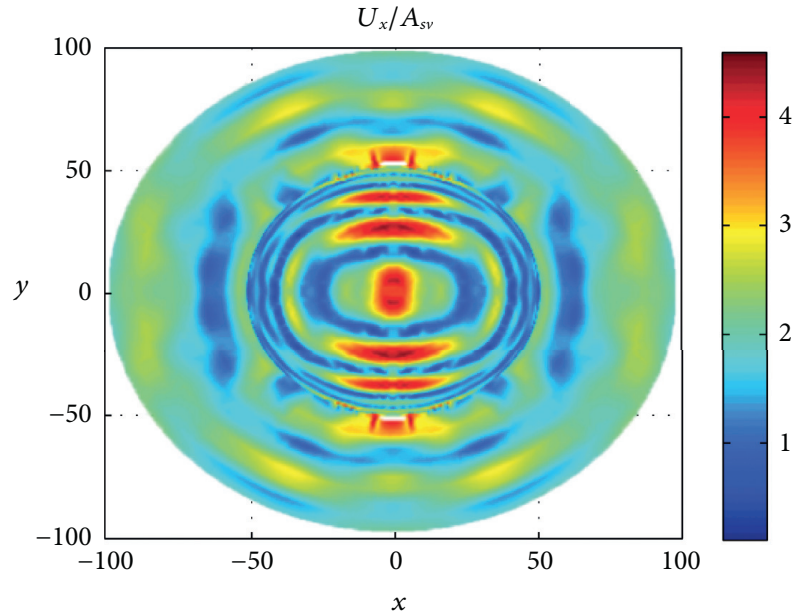

(a)

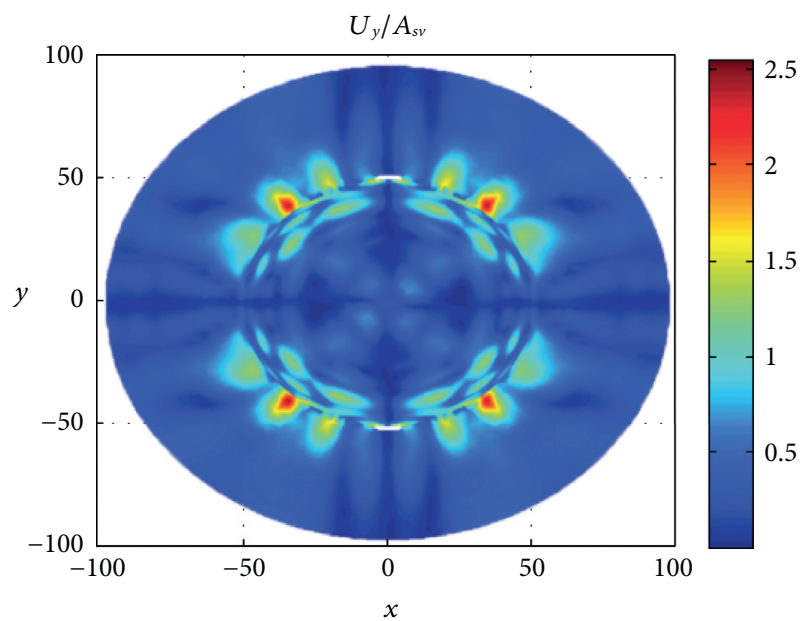

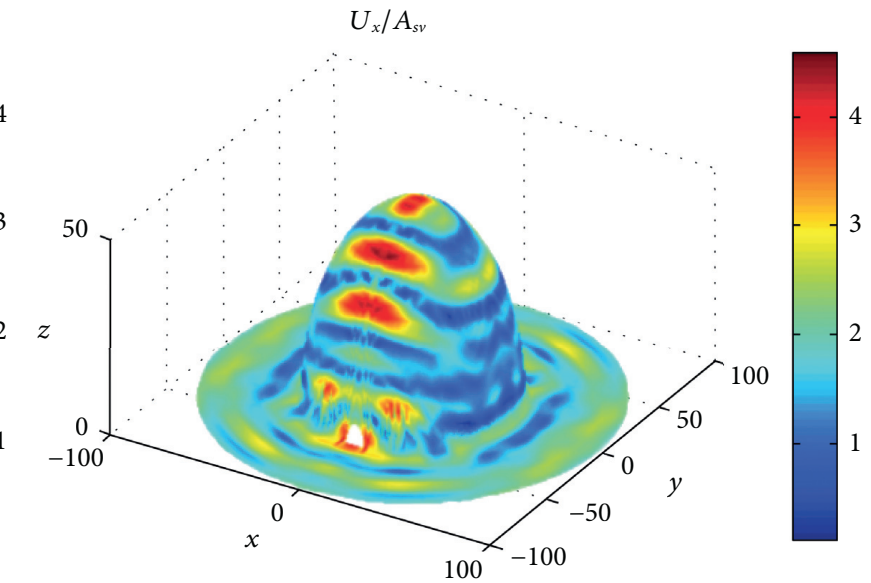

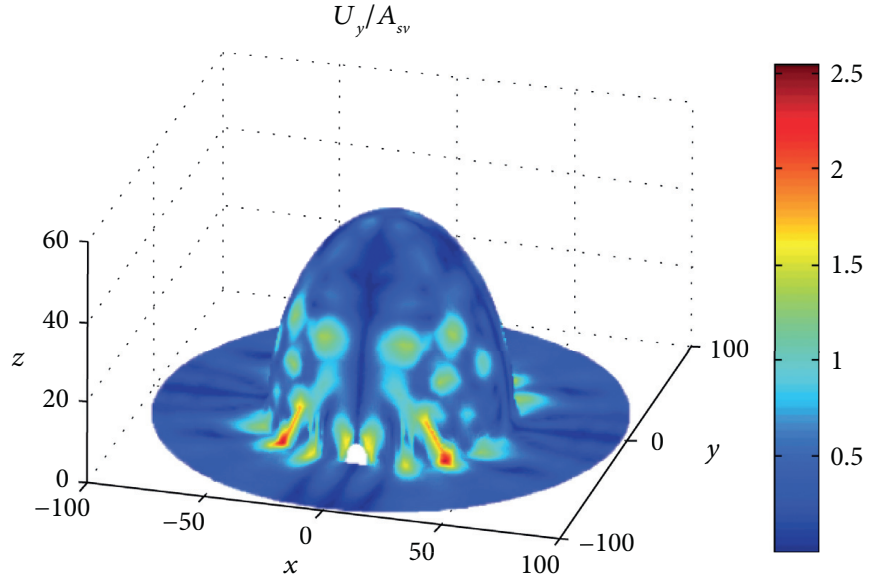

(b)

FIGURE 14: Continued. 

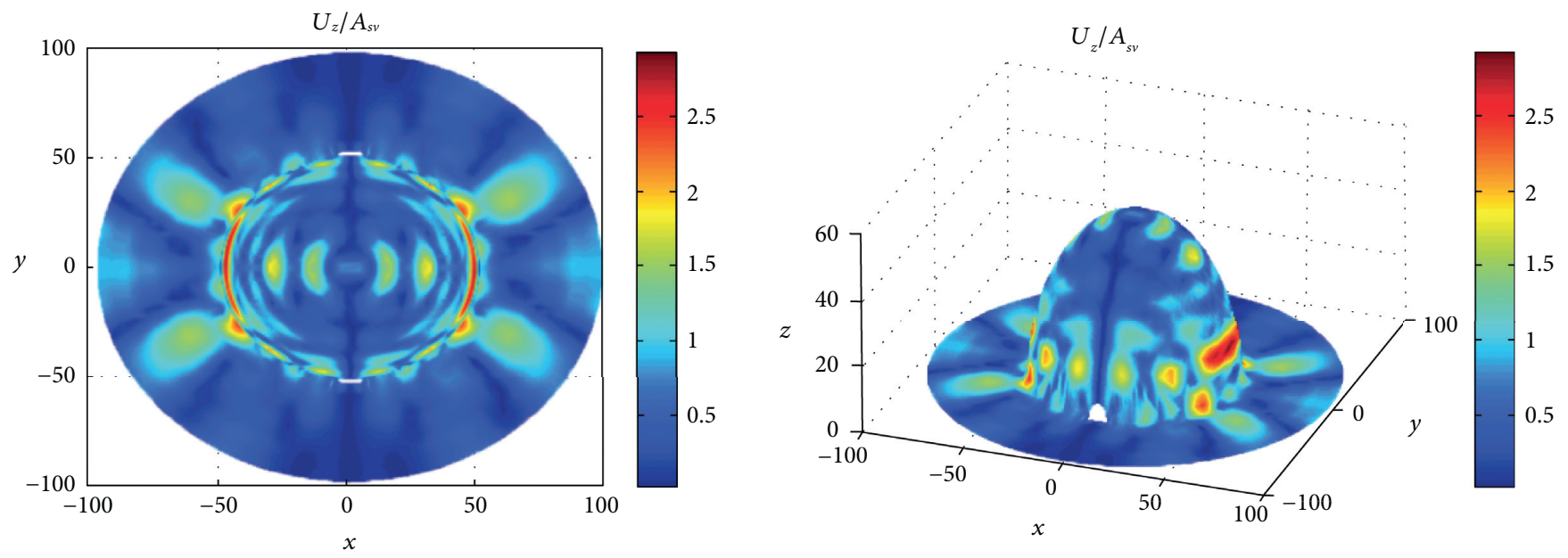

(c)

FIGURE 14: Surface displacement amplitude of the 3D tunnel mountain under the incident SV wave $\left(\eta=5.0, \alpha=0^{\circ}\right)$ : (a) surface displacement amplitude in $x$ direction; (b) surface displacement amplitude in $y$ direction; (c) surface displacement amplitude in $z$ direction.
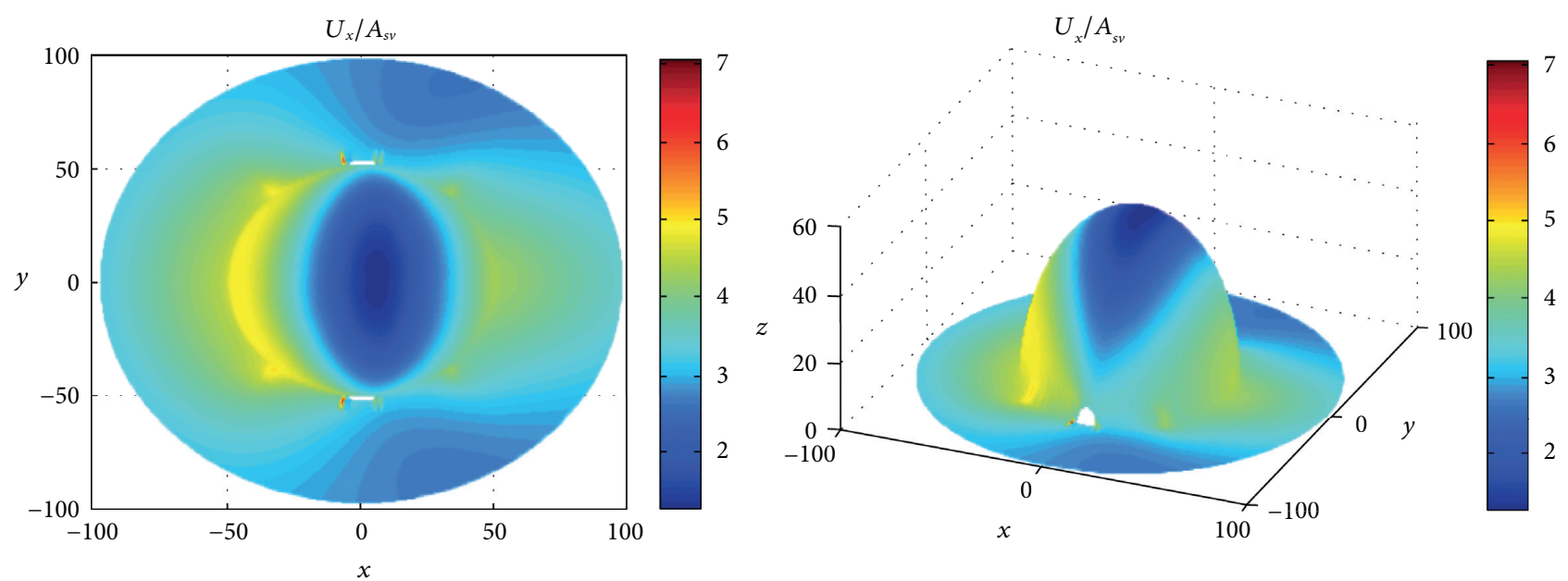

(a)
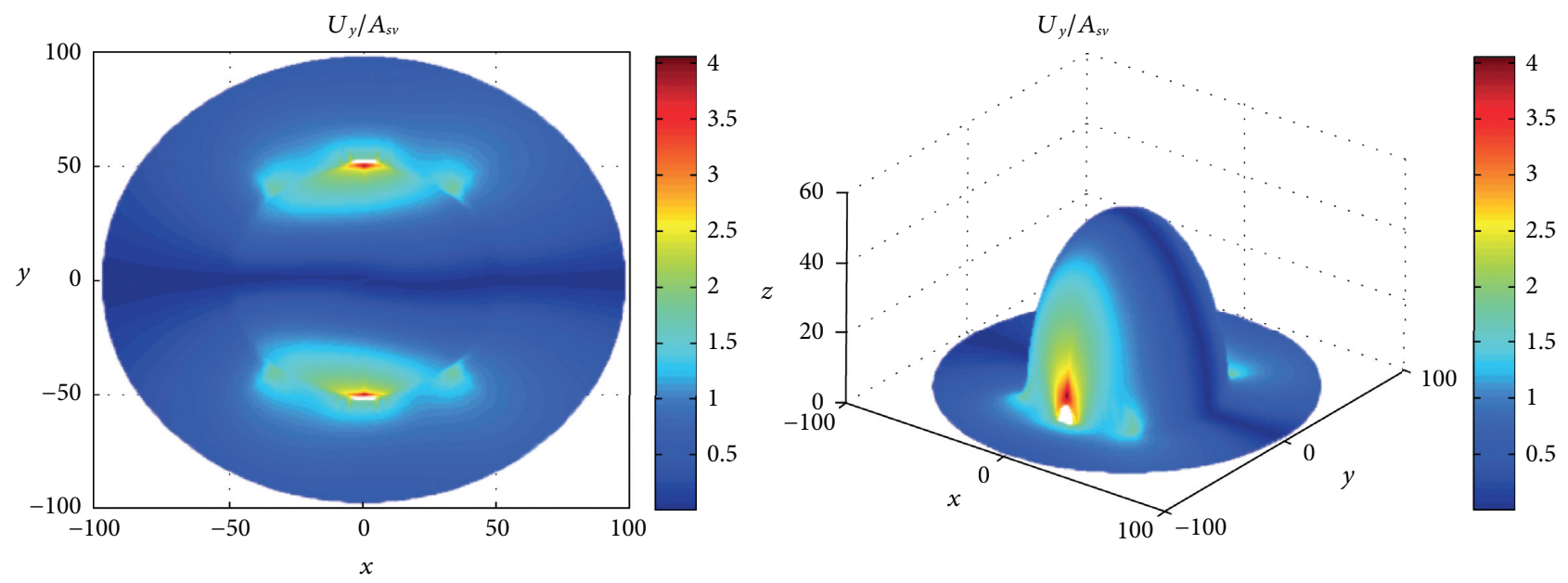

(b)

FIGURE 15: Continued. 

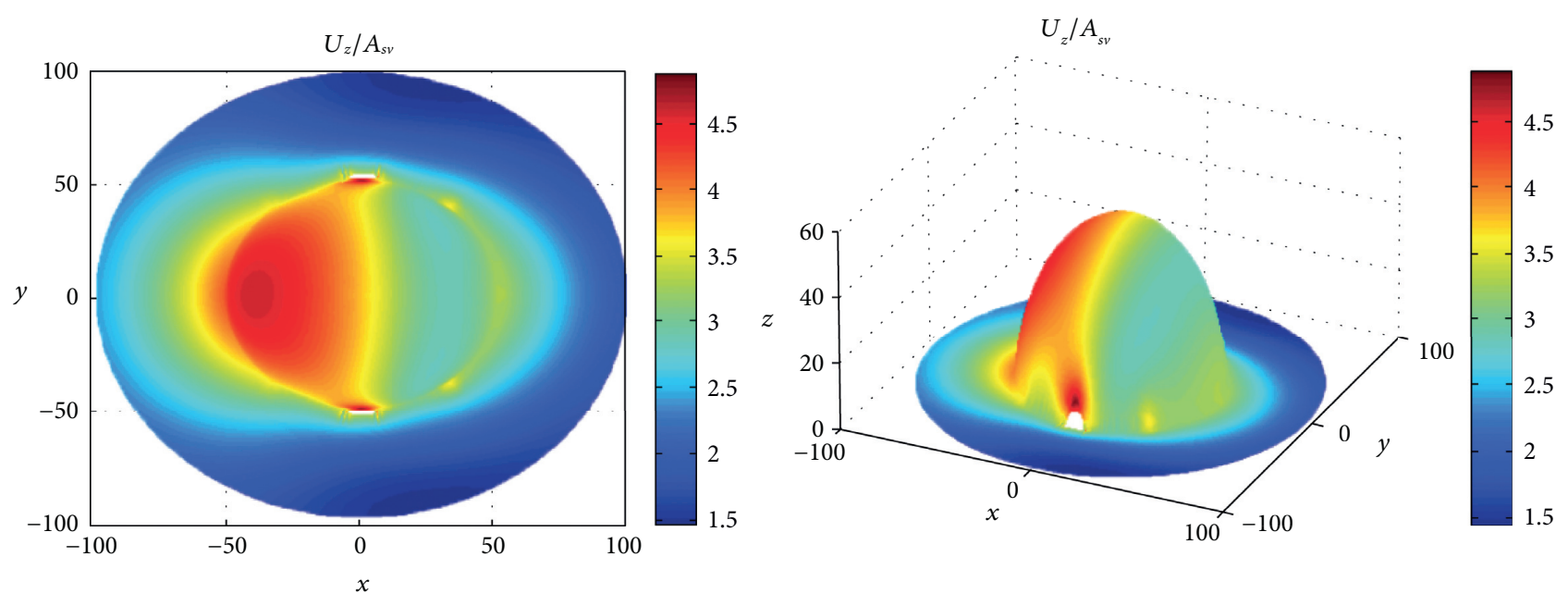

(c)

FIGURE 15: Surface displacement amplitude of the 3D tunnel mountain under the incident SV wave $\left(\eta=0.5, \alpha=30^{\circ}\right)$ : (a) surface displacement amplitude in $x$ direction; (b) surface displacement amplitude in $y$ direction; (c) surface displacement amplitude in $z$ direction.
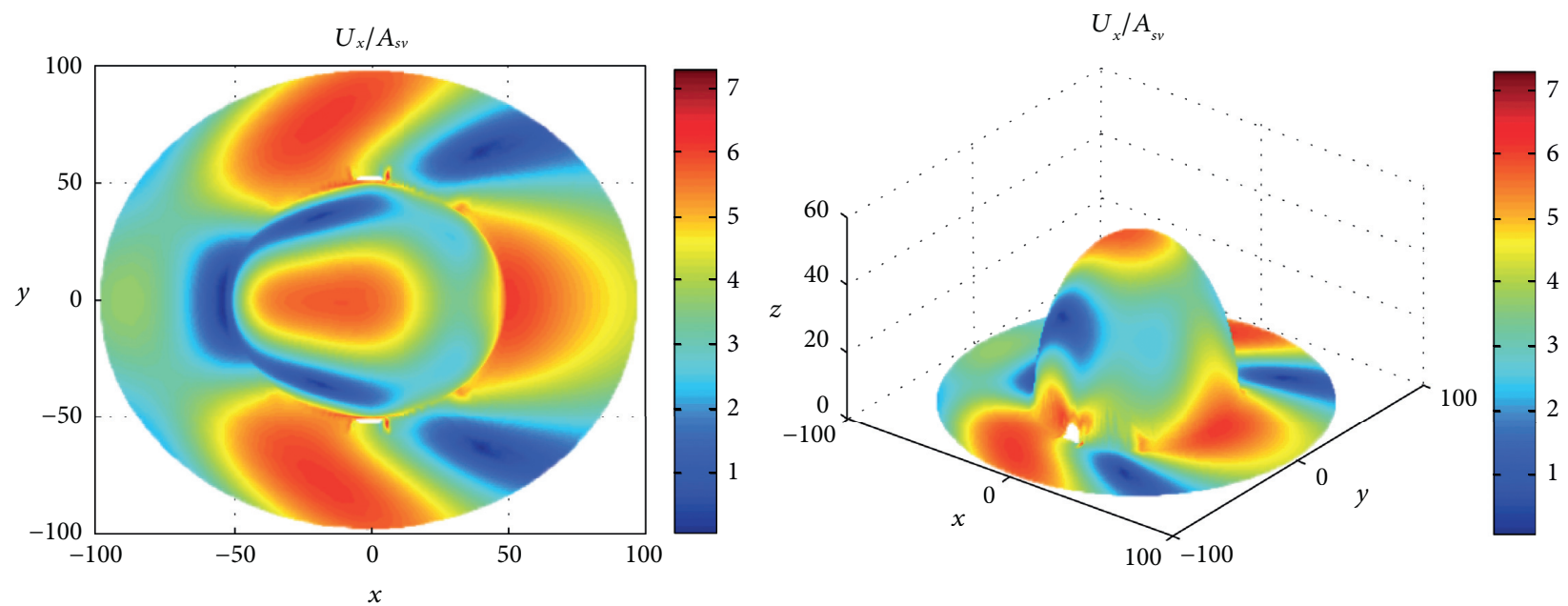

(a)

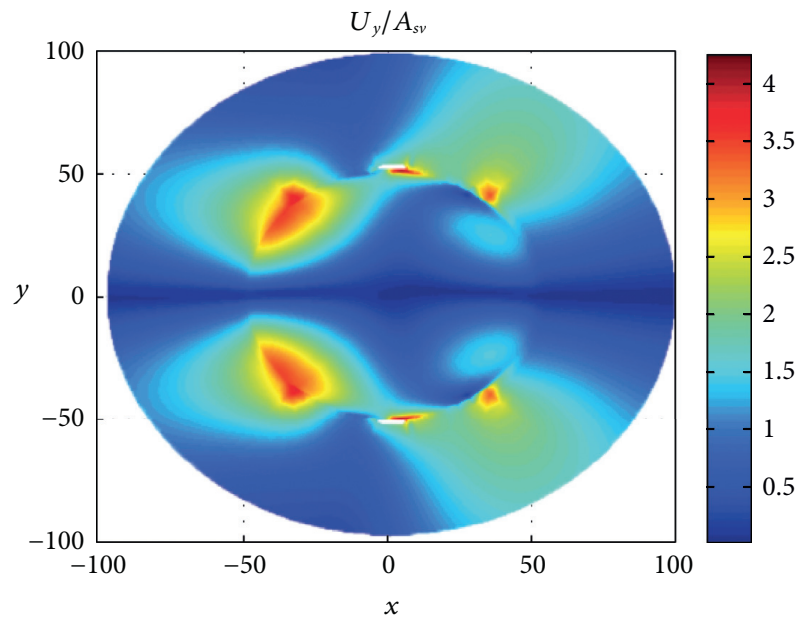

$U_{y} / A_{s v}$

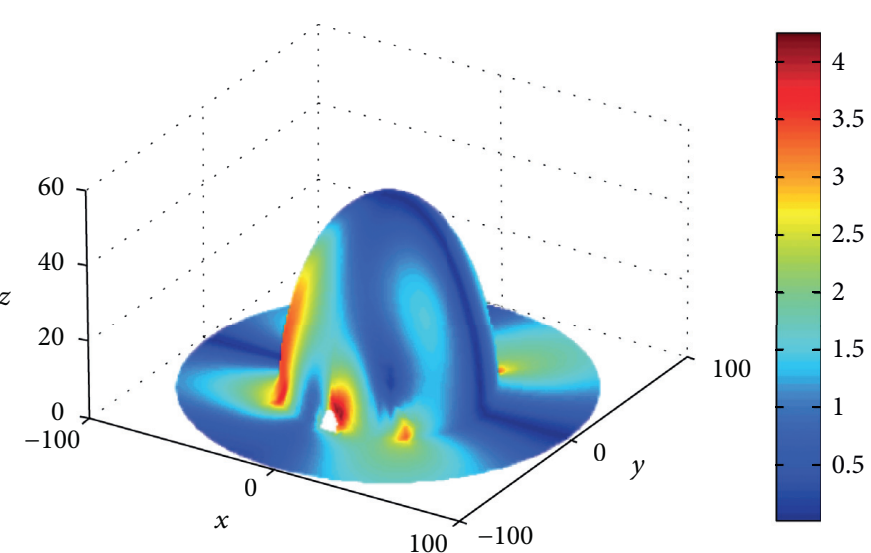

(b)

Figure 16: Continued. 

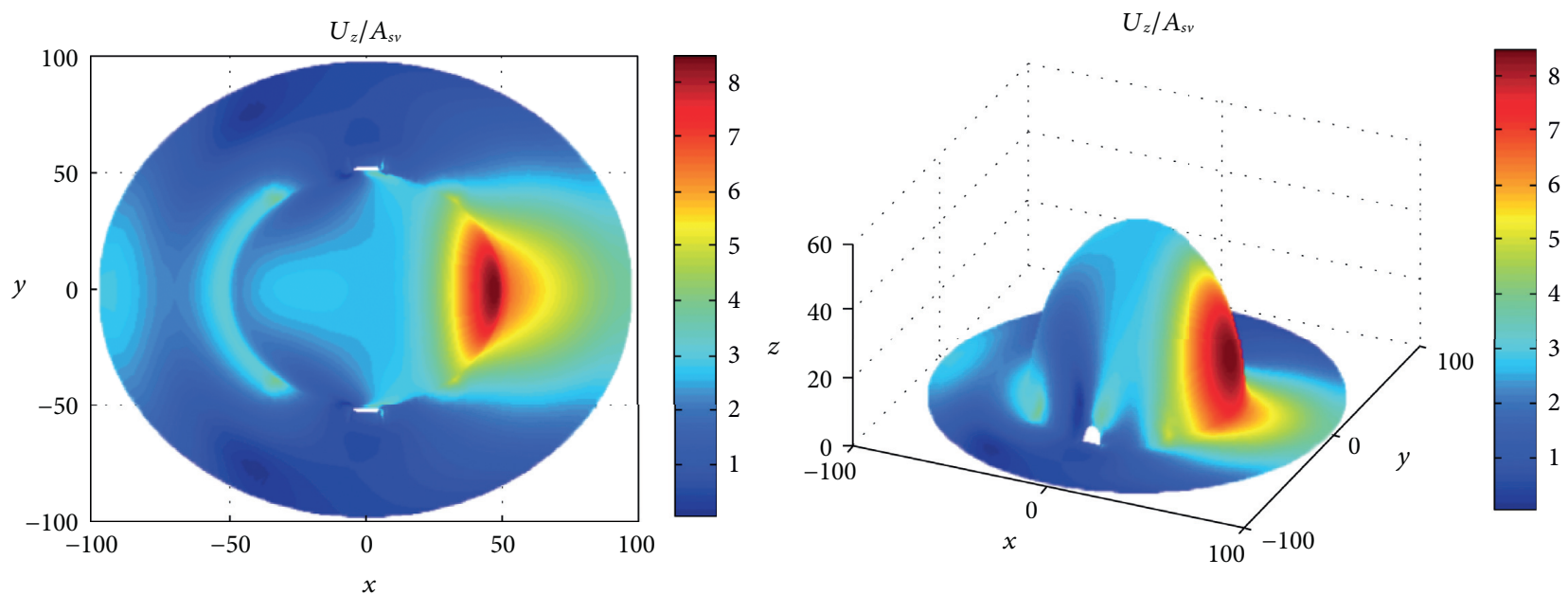

(c)

Figure 16: Surface displacement amplitude of the 3D tunnel mountain under the incident SV wave $\left(\eta=1.0, \alpha=30^{\circ}\right)$ : (a) surface displacement amplitude in $x$ direction; (b) surface displacement amplitude in $y$ direction; (c) surface displacement amplitude in $z$ direction.
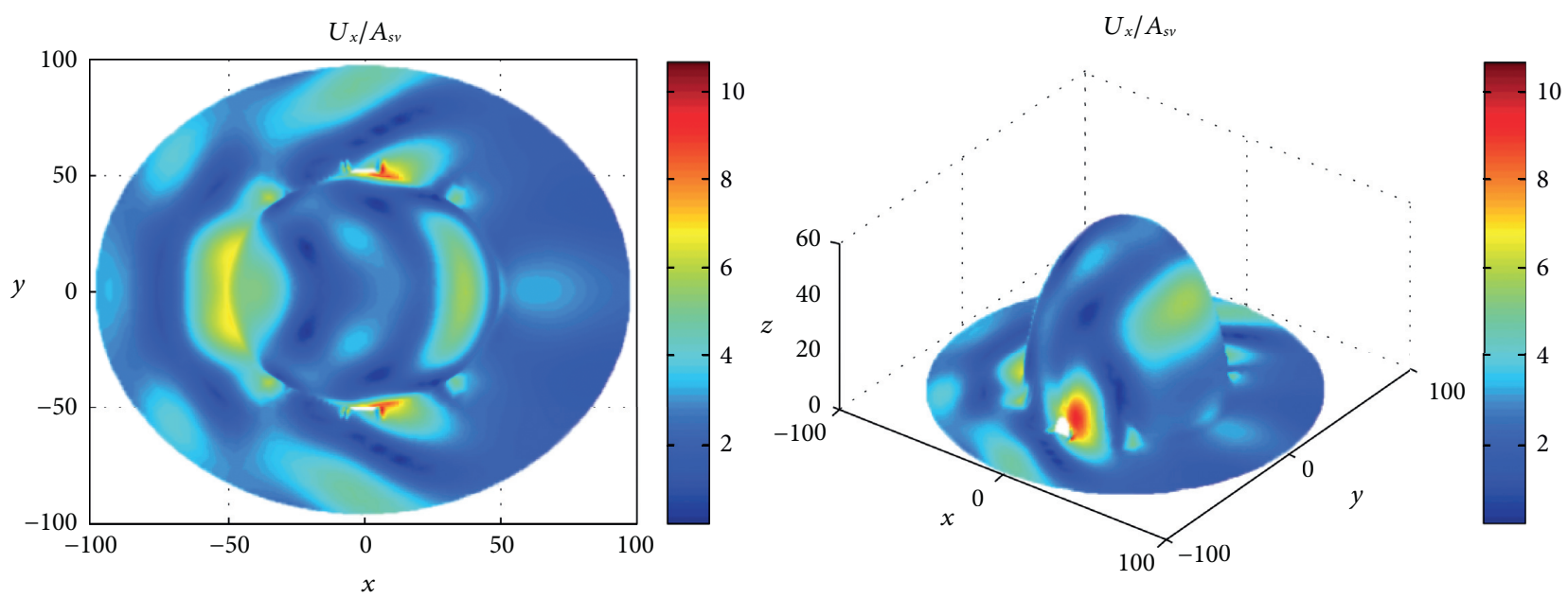

(a)
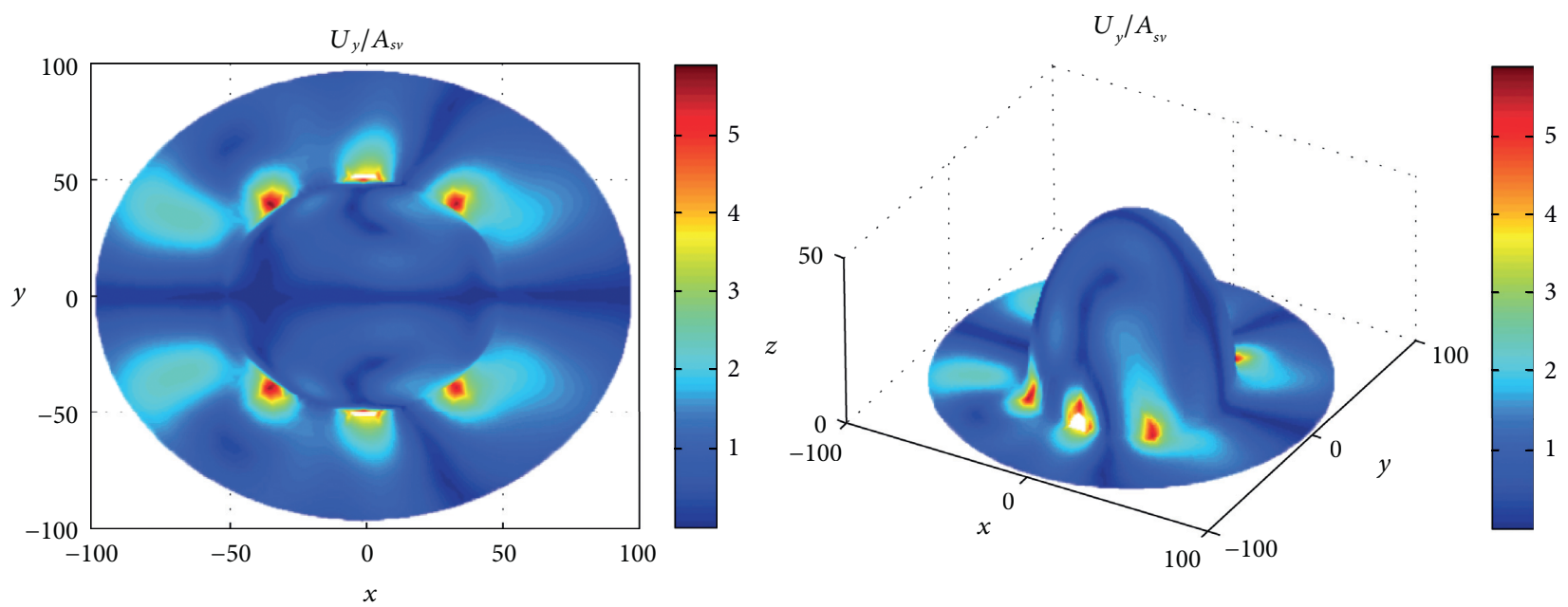

(b)

Figure 17: Continued. 

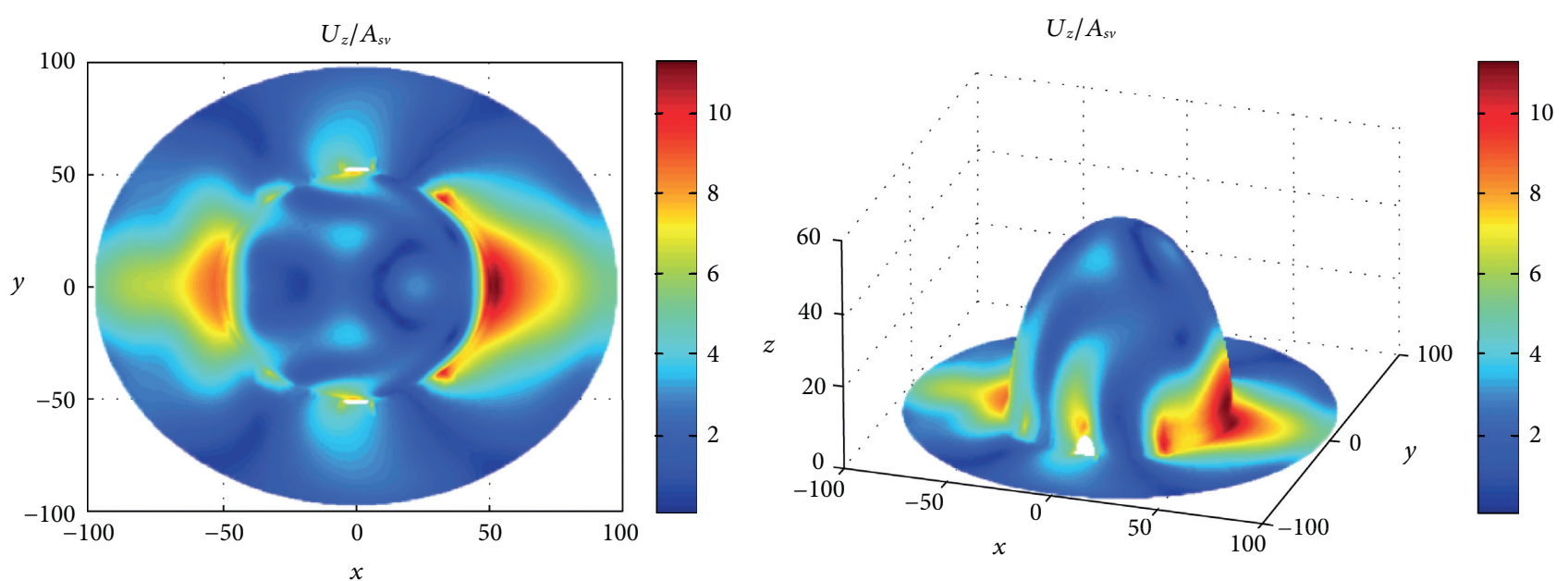

(c)

FIGURE 17: Surface displacement amplitude of the 3D tunnel mountain under the incident SV wave $\left(\eta=2.0, \alpha=30^{\circ}\right)$ : (a) surface displacement amplitude in $x$ direction; (b) surface displacement amplitude in $y$ direction; (c) surface displacement amplitude in $z$ direction.
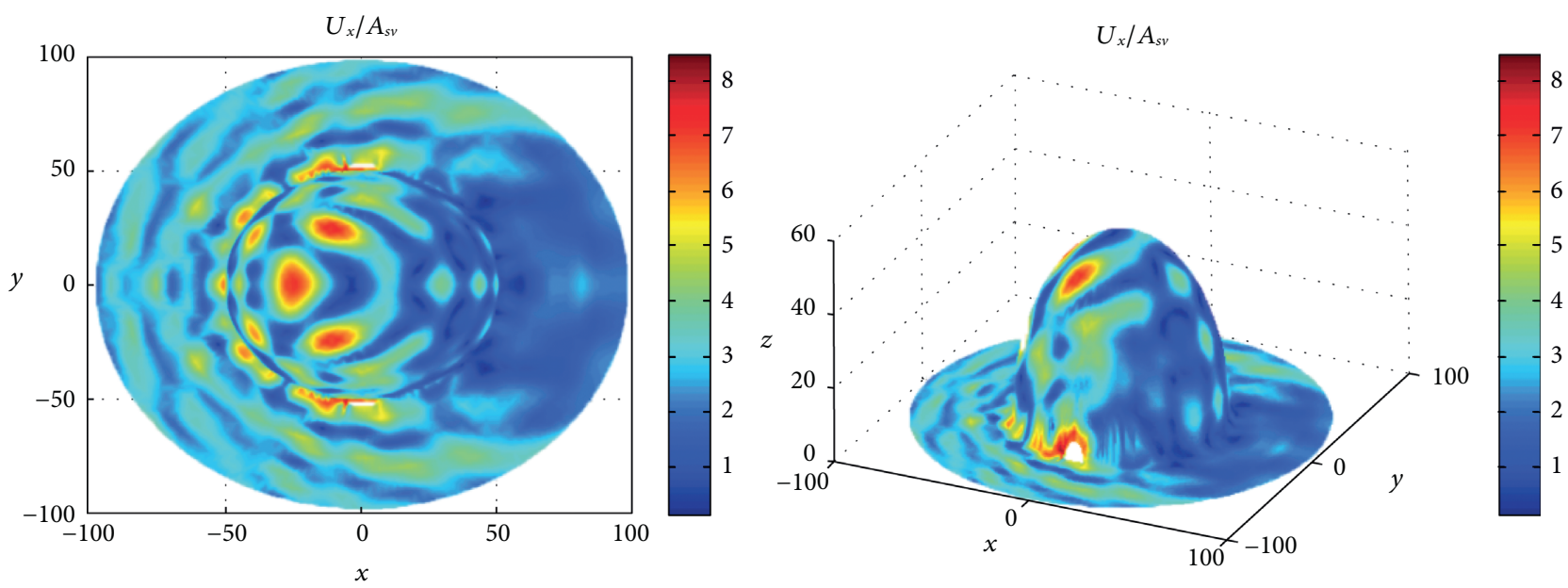

(a)
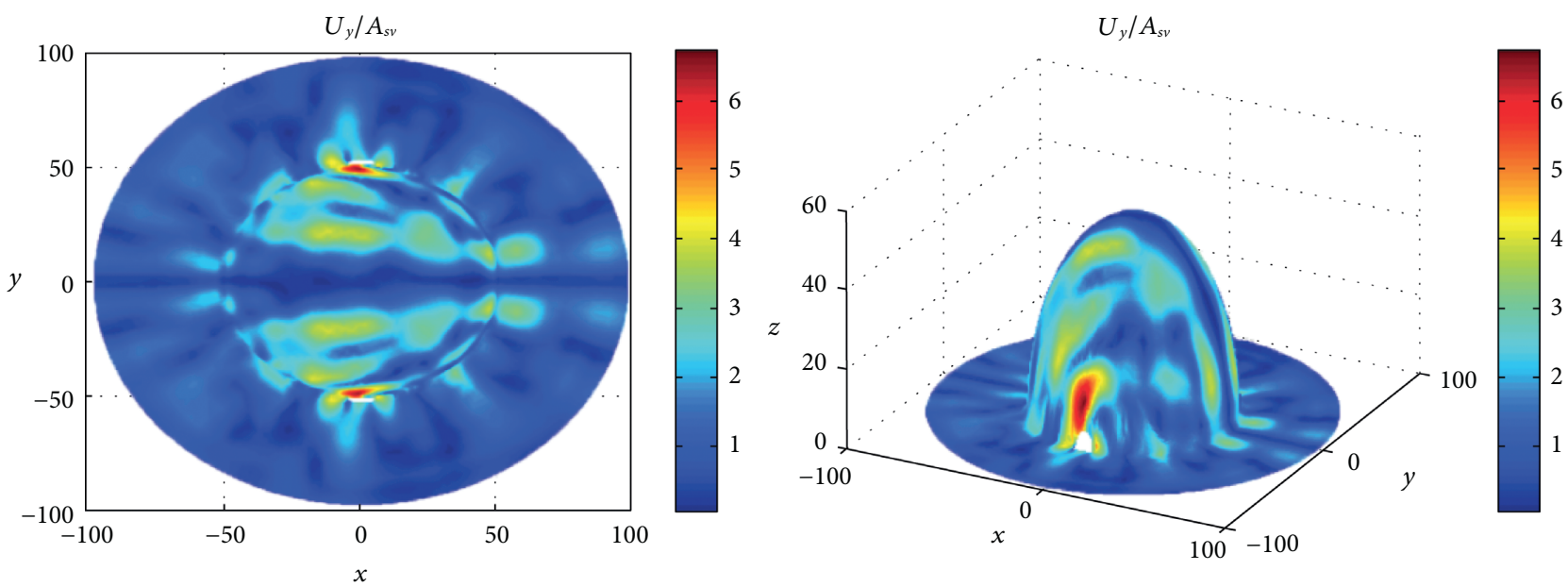

(b)

Figure 18: Continued. 

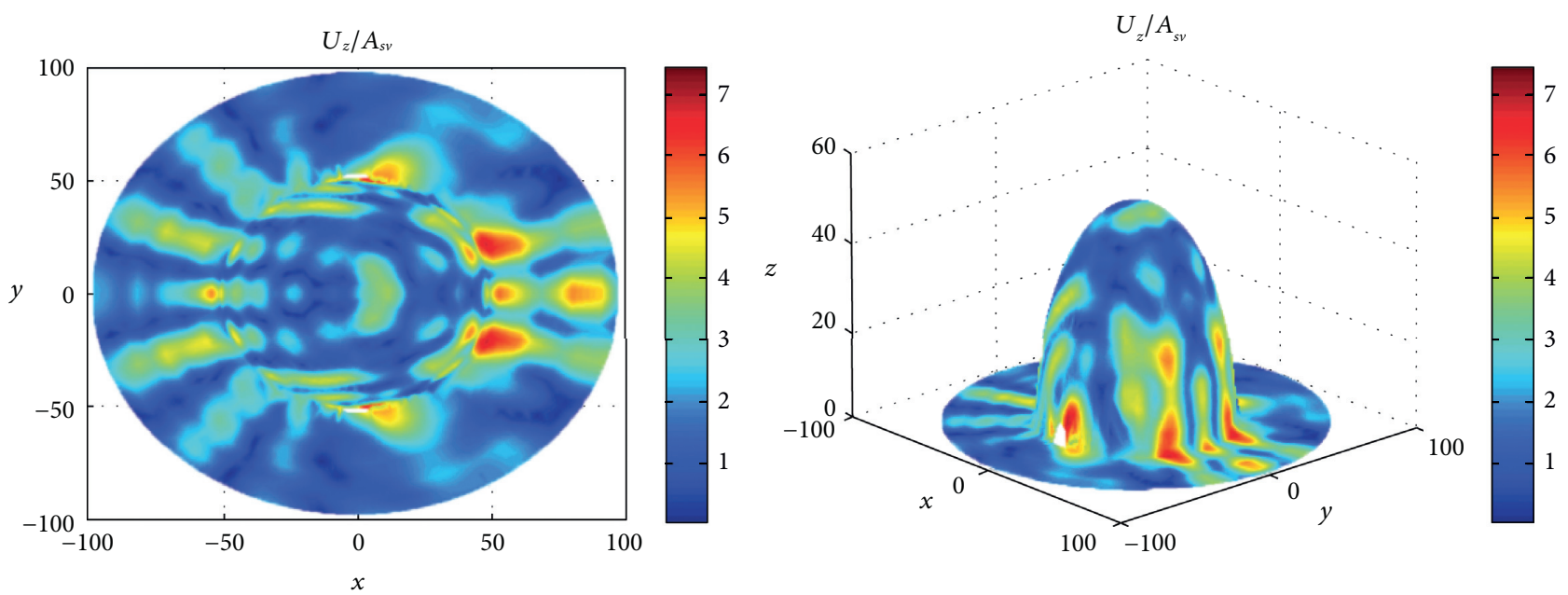

(c)

FIGURE 18: Surface displacement amplitude of the 3D tunnel mountain under the incident SV wave $\left(\eta=5.0, \alpha=30^{\circ}\right)$ : (a) surface displacement amplitude in $x$ direction; (b) surface displacement amplitude in $y$ direction; (c) surface displacement amplitude in $z$ direction.

mountain in $x$ direction appears near the tunnel entrance; for example, for $\eta=1$, the peak displacement near the tunnel entrance reaches 12.7 (see Figure 12(a)).

For the case of lower frequency incidence of SV wave, The peak displacements in the secondary directions $y$ and $z$ mostly appear near the interface between the horizontal surface and the mountain, as illustrated in Figure 11(b); for $\eta=0.5$, the maximum displacement in $y$ direction appears near $45^{\circ}$ in each quadrant of the interface between the mountain and the ground, and its value is about 1.6. Considering the high frequency incidence (see Figure 14), the scattering waves interfere strongly with each other, the phenomenon of multiple displacement peaks occurs, and, in particular, the location of peak displacements in $x$ direction appears at the tunnel entrance, which is unfavorable to the earthquake resistance of tunnels.

When the SV wave is incident at $\alpha=30^{\circ}$, the surface displacement amplitudes of the 3D tunnel mountain at individual frequency are shown in Figures 15-18. When the incidence frequency is lower, the amplification of the seismic wave in both the principal direction $x$ and the secondary directions $y$ and $z$ is greater than that for the case of the vertical incidence and is particularly obvious in $x$ direction; for example, for $\eta=0.5$, the value of peak displacement is 3.5 for the vertical incidence (see Figure 11(a)); however, the value of peak displacement reaches 7 (twice as much as the vertical incidence) for the incidence at $\alpha=30^{\circ}$ (see Figure 15(a)), and the location of peak displacement is at one side of the tunnel entrance.

Through the above analysis, it is well known that the incidence direction of wave has a significant effect on the distribution of peak displacement. Therefore, the incidence direction of the seismic wave should be considered in the seismic fortification and analysis. In addition, the comprehensive evaluation should be conducted for the urban plan and the earthquake resistance of structure in mountainous areas.

\section{Conclusions}

In this paper, based on the elastic wave theory combined with the idea of "zonal fit," the wave scattering by the 3D tunnel mountain under the incident $\mathrm{P}$ and SV waves is examined by the indirect boundary element method (IBEM). The following conclusions can be drawn through the numerical analysis:

(1) The amplification of surface displacement amplitude of the 3D mountain is strongly influenced by the incidence frequency of wave, the incidence direction of wave, the wave type, and especially the existence of the tunnel excavated in the mountain.

(2) For the vertically incident $\mathrm{P}$ wave, the maximum displacement in $z$ direction appears on the mountain top, and the amplification of surface displacement near the tunnel entrance is also significant. For the oblique incidence, the peak location moves from the mountain top to one side of the mountain. As the incidence frequency of wave increases, the amplification area is gradually reduced, and the displacement extremisms appear alternately along the tunnel extension.

(3) For the incident SV wave, the amplification of surface displacement in $x$ direction near the tunnel entrance is also significant. For the vertical incidence, the value of peak displacement can reach 12.4, and the spatial distribution is symmetrical about the tunnel axis. In addition, the amplification at the oblique incidence is greater than that at the vertical incidence and is particularly obvious along the tunnel axis.

(4) The presence of the tunnel in the mountain may cause the greater amplification, which is unfavorable to not only the mountain projects but also the tunnel. The mountain projects may suffer more severe 
damage under the incident $\mathrm{P}$ wave, while the tunnel suffers more severe damage under the incident SV wave. Therefore, the amplification should be paid enough attention to in the earthquake resistance of tunnel mountain engineering.

\section{Data Availability}

The test data used to support the findings of this study are available from the corresponding author upon request.

\section{Conflicts of Interest}

The authors declare that they have no conflicts of interest.

\section{Acknowledgments}

This study was financially supported by the National Natural Science Youth Fund of China (Grant no. 51608521), the National Natural Science Foundation of China (Grant no. 51878108), the Key Projects of Tianjin Science and Technology Support Program (17YFZCSF01140), and the Projects of Tianjin Science and Technology Program (19PTZWHZ00080).

\section{References}

[1] D. W. Griffiths and G. A. Bollinger, "The effect of Appalachian Mountain topography on seismic waves," Bulletin of the Seismological Society of America, vol. 69, no. 4, pp. 1081-1105, 1979.

[2] L. Geli, P. Y. Bard, and B. Jullien, "The effect of topography on earthquake ground motion: a review and new results," Bulletin of the Seismological Society of America, vol. 78, no. 1, pp. 42-63, 1988.

[3] M. Bouchon and J. S. Barker, "Seismic response of a hill: the example of Tarzana, California," Bulletin of the Seismological Society of America, vol. 86, no. 1A, pp. 66-72, 1996.

[4] M. Pischiutta, G. Cultrera, A. Caserta, L. Luzi, and A. Rovelli, "Topographic effects on the hill of Nocera Umbra, central Italy," Geophysical Journal International, vol. 182, no. 2, pp. 977-987, 2010.

[5] A. Amornwongpaibun, H. Luo, and V. W. Lee, "Scattering of anti-plane (SH) waves by a shallow semi-elliptical hill with a concentric elliptical tunnel," Journal of Earthquake Engineering, vol. 20, no. 3, pp. 363-382, 2016.

[6] R. D. Borcherdt, "Effects of local geology on ground motion near san francisco bay," Bulletin of the Seismological Society of America, vol. 60, no. 1, pp. 29-61, 1970.

[7] F. J. Sánchez-Sesma, M. A. Bravo, and I. Herrera, "Surface motion of topographical irregularities for incident P, SV, and Rayleigh waves," Bulletin of the Seismological Society of America, vol. 75, no. 1, pp. 263-269, 1985.

[8] J. B. Liu, "The effect of local irregular topography on ground motion in earthquake," Acta Seismologica Sinica, vol. 18, no. 2, pp. 239-245, 1996.

[9] S. Ma, R. J. Archuleta, and M. T. Page, "Effects of large-scale surface topography on ground motions, as demonstrated by a study of the San Gabriel mountains, Los angeles, California," Bulletin of the Seismological Society of America, vol. 97, no. 6, pp. 2066-2079, 2007.

[10] S.-J. Lee, D. Komatitsch, B.-S. Huang, and J. Tromp, "Effects of topography on seismic-wave propagation: an example from northern Taiwan," Bulletin of the Seismological Society of America, vol. 99, no. 1, pp. 314-325, 2009.

[11] C. Smerzini, J. Avilés, R. Paolucci, and F. J. Sánchez-Sesma, "Effect of underground cavities on surface earthquake ground motion under SH wave propagation," Earthquake Engineering \& Structural Dynamics, vol. 38, no. 12, pp. 1441-1460, 2009.

[12] Q. Liu, M. Zhao, and L. Wang, "Scattering of plane P, SV or Rayleigh waves by a shallow lined tunnel in an elastic half space," Soil Dynamics and Earthquake Engineering, vol. 49, no. 6, pp. 52-63, 2013.

[13] H. Alielahi, M. Kamalian, and M. Adampira, "Seismic ground amplification by unlined tunnels subjected to vertically propagating SV and P waves using BEM," Soil Dynamics and Earthquake Engineering, vol. 71, pp. 63-79, 2015.

[14] F. Wang, M. Miyajima, R. Dahal et al., "Effects of topographic and geological features on building damage caused by 2015.4 . 25 Mw7. 8 Gorkha earthquake in Nepal: a preliminary investigation report," Geoenvironmental Disasters, vol. 3, no. 1, pp. 1-17, 2016.

[15] H. Alielahi and M. Adampira, "Effect of twin-parallel tunnels on seismic ground response due to vertically in-plane waves," International Journal of Rock Mechanics and Mining Sciences, vol. 85, pp. 67-83, 2016.

[16] C. C. Mow and Y. H. Pao, The Diffraction of Elastic Waves and Dynamic Stress Concentrations, Rand Corp., Santa Monica, CA, USA, 1971.

[17] V. W. Lee and M. D. Trifunac, "Response of tunnels to incident SH-waves," Journal of the Engineering Mechanics Division, vol. 105, no. 4, pp. 643-659, 1979.

[18] V. W. Lee, H. Luo, and J. Liang, "Antiplane (SH) waves diffraction by a semicircular cylindrical hill revisited: an improved analytic wave series solution," Journal of Engineering Mechanics, vol. 132, no. 10, pp. 1106-1114, 2006.

[19] X. Yuan and Z.-P. Liao, "Surface motion of a cylindrical hill of circular-arc cross-section for incident plane SH waves," Soil Dynamics and Earthquake Engineering, vol. 15, no. 3, pp. 189-199, 1996.

[20] J. Liang, Y. Zhang, and V. W. Lee, "Scattering of plane P waves by a semi-cylindrical hill: analytical solution," Earthquake Engineering and Engineering Vibration, vol. 4, no. 1, pp. 2736, 2005.

[21] J.-w. Liang, Y.-s. Zhang, and V. W. Lee, "Surface motion of a semi-cylindrical hill for incident plane SV waves: analytical solution," Acta Seismologica Sinica, vol. 19, no. 3, pp. 251-263, 2006.

[22] J. Liang and Z. Ba, "Surface motion of a hill in layered halfspace subjected to incident plane $\mathrm{SH}$ waves," Earthquake Engineering and Engineering Vibration, vol. 28, no. 1, pp. 1-10, 2008.

[23] J. Liang and J. Fu, "Surface motion of a semi-elliptical hill for incident plane SH waves," Earthquake Science, vol. 24, no. 5, pp. 447-462, 2011.

[24] M. Fuyuki and Y. Matsumoto, "Finite difference analysis of Rayleigh wave scattering at a trench," Bulletin of the Seismological Society of America, vol. 70, no. 6, pp. 2051-2069, 1980.

[25] A. Frankel and J. Vidale, "A three-dimensional simulation of seismic waves in the Santa Clara Valley, California, from a Loma Prieta aftershock," Bulletin of the Seismological Society of America, vol. 82, no. 5, pp. 2045-2074, 1992.

[26] S.-J. Lee, H.-W. Chen, and B.-S. Huang, "Simulations of strong ground motion and $3 \mathrm{D}$ amplification effect in the Taipei Basin by using a composite Grid finite-difference 
method," Bulletin of the Seismological Society of America, vol. 98, no. 3, pp. 1229-1242, 2008.

[27] Z. P. Liu, B. P. Yang, and Y. F. Yuan, "Effects of three-dimensional topography on earthquake ground motion," Earthquake Engineering and Engineering Vibration, vol. 1, pp. 56-77, 1981.

[28] Q. F. Liu, Y. Y. Yu, and X. B. Zhang, "Three-dimensional ground motion simulation for Shidian Basin," Earthquake Engineering and Engineering Vibration, vol. 33, no. 4, pp. 54-60, 2013.

[29] L. Huang, Z. Liu, C. Wu, and J. Liang, "The scattering of plane $\mathrm{P}, \mathrm{SV}$ waves by twin lining tunnels with imperfect interfaces embedded in an elastic half-space," Tunnelling and Underground Space Technology, vol. 85, pp. 319-330, 2019.

[30] Z. Liu, H. Zhang, A. Cheng et al., "Seismic interaction between a lined tunnel and a hill under plane SV waves by IBEM," International Journal of Structural Stability and Dynamics, vol. 19, no. 2, pp. 195-204, 2019.

[31] Z. Liu, L. Huang, J. Liang, and C. Wu, "A three-dimensional indirect boundary integral equation method for modeling elastic wave scattering in a layered half-space," International Journal of Solids and Structures, vol. 169, pp. 81-94, 2019.

[32] J. Liang, Z. Liu, L. Huang, and G. Yang, "The indirect boundary integral equation method for the broadband scattering of plane P, SV and Rayleigh waves by a hill topography," Engineering Analysis with Boundary Elements, vol. 98, pp. 184-202, 2019.

[33] X. J. Li and T. Lu, "Explicit finite element analysis of earthquake response for underground caverns of hydropower stations," Journal of Hydroelectric Engineering, vol. 28, no. 5, pp. 41-46, 2009.

[34] Z. Q. Zhu, Q. Sheng, Z. J. Chen, and J. H. Li, "Influence of mountain topographic and geological structural plane on seismic response of rock cavern," Chinese Journal of Rock Mechanics and Engineering, vol. 36, no. S1, pp. 3509-3515, 2017.

[35] M. H. Hao and Y. S. Zhang, "Analysis of the adjacent terrain effect on the properties of ground motion," Earthquake Research in China, vol. 31, no. 4, pp. 656-667, 2015.

[36] H. Zhou and X. F. Chen, "An new approach to simulate scattering of $\mathrm{SH}$ waves by an irregular topography," Geophysical Journal International, vol. 164, no. 2, pp. 444-459, 2006.

[37] H. Zhou and X. Chen, "The Localized boundary integral equation-discrete Wavenumber method for simulating P-SV wave scattering by an irregular topography," Bulletin of the Seismological Society of America, vol. 98, no. 1, pp. 265-279, 2008.

[38] Z. X. Liu, X. Zhang, S. J. Sun, and Z. K. Wang, "Boundary element method simulation for seismic dynamic interaction of adjacent mountain terrain," Chinese Journal of Applied Mechanics, vol. 35, no. 4, pp. 722-729+928, 2018.

[39] H. Kawase and K. Aki, "A Study on the response of a soft basin for incident S, P and Rayleigh waves with special reference to the long duration observed in Mexico city," Bulletin of the Seismological Society of America, vol. 79, no. 5, pp. 1361-1382, 1989.

[40] F. J. Sánchez-Sesma, "Diffraction of elastic waves by threedimensional surface irregularities," Bulletin of the Seismological Society of America, vol. 73, no. 6A, pp. 1621-1636, 1983.

[41] A. Sohrabi-Bidar, M. Kamalian, and M. K. Jafari, "Timedomain BEM for three-dimensional site response analysis of topographic structures," International Journal for Numerical Methods in Engineering, vol. 79, no. 12, pp. 1467-1492, 2009. 